\title{
Formulation and investigation of crushed puffed rice-chitosan-HPMC based polymeric blends as carrier for sustained stomach specific drug delivery of piroxicam using 3(2) Taguchi mathematical design studies
}

\author{
*Shashank Soni ${ }^{1,2}$, Veerma Ram ${ }^{1}$ and Anurag Verma ${ }^{2}$ \\ ${ }^{1}$ School of Pharmaceutical Sciences, Sardar Bhagwan Singh PG Institute of Biomedical Sciences and Research, Balawala, Dehradun, India \\ ${ }^{2}$ School of Pharmaceutical Sciences, IFTM University, Moradabad, India
}

\begin{abstract}
In the present experimental investigation an attempt has been made to assess the utility of Crushed Puffed Rice (CPR)-High Molecular Weight Chitosan (HMWCH)-Hydroxypropyl Methylcellulose K15M (HPMC K15M) as a polymeric carrier for the sustained stomach delivery of Piroxicam (PRX). A total of nine formulations were prepared by using 3 (2) Taguchi factorial design, physically blending drug and polymer(s) followed by encapsulation into hard gelatin capsules size 1 . The prepared capsules were evaluated for various performance such as weight variation, drug contents, in vitro buoyancy and drug release in $0.1 \mathrm{M} \mathrm{HCl}$. The effect of drug loading on in vitro performance of the formulations was also determined. Crushed puffed rice $(\mathrm{CPR})$ remained buoyant for up to average time span of $06 \mathrm{hr}$ as an unwetted irregular mass in $0.1 \mathrm{M} \mathrm{HCl}$. However, when combined with HMWCH or HPMC K15M or HPMC K15M + HMWCH a low -density cylindrical raft type hydrogel was formed which remained buoyant for up to $12 \mathrm{hr}$ and released up to $99 \%$ drug in a sustained manner from 8 to $12 \mathrm{hr}$ following zero order release kinetics. It was also observed that drug release from drug + CPR matrices followed Fickian mechanism. Combination of CPR + HMWCH or HMWCH + HPMC K15M also follows Fickian mechanism. Obtained data from the research work suggests that CPR in combination with HMWCH or HPMC K15M or HPMC has sufficient potential to be used as a carrier for stomach specific delivery of gastric irritant drug like PRX.
\end{abstract}

Key Words: Crushed Puff Rice, Chitosan, HPMC, Piroxicam, drug release mechanism.

\section{INTRODUCTION}

Puffed rice (Oryza sativa) is a common snack in India. These are very crispy in nature and are prepared by air frying preboiled dehusked rice in clay ovens at very high temperature. Chemically, it contains carbohydrates as a major constituent (Kizil et al., 2003; Huang et al., 2007; Santha et al., 1990). Since these are crispy in nature, they can be crushed into fine low-density powder which is not easily wetted by water and can float over the surface for a prolonged period of time. This property of puffed rice motivated us to use it as buoyancy imparting agent in gastroretentive drug delivery system and if possible as a release retarding polymer.

In recent years of research, Chitosan $(\mathrm{CH})$ mixtures with non-ionic polymers have received much attention because they show better improved physicochemical properties in comparison to the other polymer. In order to increase the stability of polymeric material, numerous studies have been reported by the researchers on the binary mixtures of $\mathrm{CH}$ with natural (starch), poly (ethylene oxide), polyvinylopyrrolidone (PVP) polymers, synthetic poly (vinyl alcohol) (Jarry et al., 2002; Mucha et al., 2005; Cervera et al., 2004; Khoo et al., 2003; Verma et al., 2016). Combination of HPMC K15 and $\mathrm{CH}$ in the matrix system has been reported to provide retardation in the drug release profile by one of the author of presented research work (Soni et al., 2016; Soni et al., 2017a). This retardation has been attributed

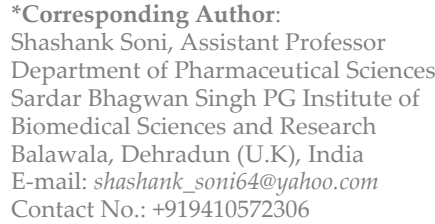

to a development of stronger hydrogel layer of the resultant matrix polymer, reducing diffusion and erosion rate of the hydrogel structure (Haug et al., 1967; Soni et al., 2016; Soni et al., 2017a).

The current research investigation is, therefore, envisaged to explore the potential of Crushed puffed rice (CPR) as a buoyancy imparting agent and drug delivery carrier alone and in combination with polymers, viz. High Molecular Weight Chitosan (HMWCH) and Hydroxypropyl Methylcellulose K15 (HPMC K15M) (Soni et al., 2017a; Soni et al., 2016). The reason for selecting $\mathrm{HMWCH}$ (cationic) and HPMC K15M (non-ionic) as other polymers used in the study is based upon our previous work with these polymers (Soni et al., 2016; Soni et al., 2017a). Both of these polymers can swell in aqueous acidic dissolution medium to form low-density hydrogels which float over the surface of dissolution medium. In past, we have successfully explored these polymers with PRX and Metoprolol Succinate (MS) found that release of drug from polymeric matrix composed of these polymers occurred by a dual combination of diffusion and erosion (Soni et al., 2016; Soni et al., 2017a).

In this work, we have combined CPR with these gelforming polymers. Since CPR is expected to provide buoyancy imparting properties, it can form a raft over which HMWCH or HPMC or their combination will form the hydrogel network. This will not only reduce the concentration of HMWCH and HPMC in the polymeric matrices but also expected to modulate the release mechanism from predominantly diffusion and erosion to predominantly diffusion due to a slow erosion of passenger gel-forming polymers (Soni et al., 2017a). In this research work, a number of Hydrodynamically balanced (HBS) capsule formulations containing mixtures of CPR with HMWCH or HPMC $\mathrm{K} 15 \mathrm{M}$ or HMWCH+HPMC K15M with PRX were prepared 
by physical blending and the encapsulated in hard gelatin capsules (size 1). Piroxicam (PRX) was used as the model drug. Piroxicam is frequently used NSAID (non-steroidal anti-inflammatory drug) for long-term treatment of chronic diseased conditions like osteoarthritis, rheumatoid arthritis, and so forth to improve patient's quality of life and ability to function. Like all NSAIDs, PRX is also associated with elevated risk of gastrointestinal toxicity such as ulcers and bleeding. The risk may be higher for the people who are older in age, have poor health, or drink a large amount of alcohol (Saxena et al., 2013). Oral delivery of such drugs through drug delivery carrier HBS capsule formulations not only prevents the direct contact of the drug with gastric mucosa but also sustains the release of embedded drug leading to better treatment efficacy, safety, and patient compliance.

\section{EXPERIMENTAL}

\section{Materials}

Piroxicam (PRX) was obtained as a gift sample from Akum's Drug and Pharmaceutical Limited, India. High Molecular Weight Chitosan (HMWCH; Degree of Deacetylation $>85 \%$, apparent viscosity $>400 \mathrm{mPa} . \mathrm{s}$ at $20^{\circ} \mathrm{C}$, Brookfield; Molecular Weight; $310-375 \mathrm{kDa}$ ) was purchased from Sigma-Aldrich; St. Louis, USA. Hydroxypropyl Methylcellulose (HPMC K15M, apparent viscosity $11250-21000 \mathrm{cP}$ at $20^{\circ} \mathrm{C}$ ) received as gift sample from Colorcon Asia Private Limited, Goa, India. Oryza Sativa (puffed rice) was purchased from local market of Dehradun, India. Dialysis membrane $1 \mathrm{kDa}$ molecular weight was purchased from Sigma Aldrich, St. Louis; USA. $0.45 \mu \mathrm{m}$ membrane filter was purchased from Rankem, India. Double distilled water was used throughout the experimental studies. All other chemicals and reagents used were of analytical grade (AR).

\section{Mathematical optimization by Taguchi design}

3 (2) factorial design was employed for this study using Taguchi design. The amount of polymers HPMC K15M (A); $\mathrm{HMWCH}(\mathrm{B})$ and CPR was selected as factors and studied at two levels. Table 1 and 5 summarizes the nine experimental runs]. Buoyancy time $\left(\mathrm{Y}_{1}\right)$ and time are taken for $60 \%$ drug release $\left(\mathrm{T} 60 \% ; \mathrm{Y}_{2}\right)$ was taken as the response variables. All these studied was performed using the Minitab-18 software.

\section{Development of CPR powder}

$\mathrm{CPR}$ was dried in the dryer at a temperature of $45^{\circ} \mathrm{C}$ to remove the moisture till the equilibrium moisture content (EMC) was achieved which was indicated by constant weight readings followed by transfer in the ball mill (Mini ball mill; model number 60, Shakti Pharmtech Pvt. Ltd) for comminution. After running time of 10 minutes the crushed CPR was collected over sheet of butter paper and transferred over a sieve \#120 for size separation to get a monodisperse powder, undersize particles were collected and stored in an airtight glass vial to prevent the entry of moisture (Soni et al., 2017a).

Preparation of Single-unit Hydrodynamically Balanced System (HBS) Capsules containing formulations by ordered mixing

Optimized formulations (Table 4 and 8) for HBS capsules were prepared ordered mixing technique by placing the drug between layers of polymers in a glass vial $(10 \mathrm{ml})$ and shaken vigorously by hand for $5 \mathrm{~min}$., followed by encapsulation in hard gelatin capsule shell (size 1) using laboratory capsule filling machine (Soni et al., 2016).

\section{Thermal characterization}

Thermal characterization was performed on EXSTAR TG/DTA 6300 and it includes characterization by Thermo Gravimetric Analysis (TGA), Differential Thermal Analysis (DTA) and Derivative Thermo Gravimetric Analysis (DTG). It was carried to study the determination of endothermic and exothermic peaks and heat of melting was recorded of the drug, excipient and drug-excipient mixtures in the investigation. The study was carried out at $5^{\circ} \mathrm{C} / \mathrm{min}$ till melting point in the presence of inert nitrogen. The flow rate of purge gas (inert gas) is $2 \mathrm{ml} /$ minute (Soni et al., 2016; Soni et al., 2017a). Physical mixtures were mixed and transferred in sealed vials for period of two months at room temperature before recording of thermogram for all samples.

Functional group characterization of drug, excipient and drug excipient composition by using Fourier Transform Infrared spectroscopy (FTIR) studies

Fourier Transform Infrared spectroscopy (FTIR) was performed on instrument BX2, Perkin Elmer, Norwalk, USA The FTIR analysis was carried out for to ascertain that there is any drug excipient interaction occurs or not and secondly to confirm the presence of the functional group in the mixtures. The method involved for sampling of direct compression technique by using potassium bromide ( $\mathrm{KBr})$. The sample pellet was mounted in FTIR compartment and taken the scan at wavelength $4000 \mathrm{~cm}^{-1}-400 \mathrm{~cm}^{-1}$ (Soni et al., 2016; Soni et al., 2017a). Physical mixtures were mixed and transferred in sealed vials for period of two months at room temperature before recording of spectra for all samples.

\section{In vitro stability studies of PRX in $0.1 \mathrm{M} \mathrm{HCl}$}

Stability studies of PRX in $0.1 \mathrm{M} \mathrm{HCl}$ was determined to assure that whether the drug will remain stable throughout the period of drug release and during gastroretention. $1 \mathrm{mg} / \mathrm{ml}, 3 \mathrm{mg} / \mathrm{ml}$ and $5 \mathrm{mg} / \mathrm{ml}$ solution of PRX is prepared in $0.1 \mathrm{M} \mathrm{HCl}$. The temperature of the USP XXIV dissolution apparatus (type II, rpm; 25) is maintained at $37 \pm 0.5^{\circ} \mathrm{C}$. One $\mathrm{ml}$ of the sample was periodically withdrawn with the help of a syringe, replaced by freshly prepared $0.1 \mathrm{M} \mathrm{HCl}$ to maintain the sink condition. The samples are suitably diluted by the same (0.1 M HCL) followed by sonication for 5 minutes and were measured at $333 \mathrm{~nm}$ (Soni et al., 2016).

\section{Estimation of drug content in formulations}

The estimation of drug concentration in each formulation was estimated in triplicate by emptying each capsule containing formulation in $0.1 \mathrm{M} \mathrm{HCl}$ at $37 \pm 0.5^{\circ} \mathrm{C}$ followed by stirring by help of stirrer for 2 hours at $200 \mathrm{rpm}$. The solution was filtered through $0.45 \mu \mathrm{m}$ filter membrane diluted suitably and analyzed at absorption maxima at $333 \mathrm{~nm}$ (Soni et al., 2016; Soni et al., 2017a).

\section{In vitro buoyancy studies}

The capsules were placed in $900 \mathrm{ml} 0.1 \mathrm{M} \mathrm{HCl}, \mathrm{pH} 1.2$ in USP XXIV type II apparatus (Electrolab; TDT-08L, Mumbai; India) at rpm 50 maintaining the temperature of $37 \pm 5^{\circ} \mathrm{C}$. The time at which the formulations remained buoyant in $0.1 \mathrm{M} \mathrm{HCl}$ was observed and was taken as the floating time (Soni et al., 2016; Soni et al., 2017a).

$\%$ weight changed of formulations using dialysis membrane after exposure in $0.1 \mathrm{M} \mathrm{HCl}$

Weighed amount of polymer and drug gently mixed by placing them in a glass vial. These mixtures were transferred to a $3 \mathrm{~cm} \times 3 \mathrm{~cm}$ dialysis bag (Sigma Aldrich) and sealed with thread from both the sides. This bag containing 
Table 1: Factor Composition using 3(2) Taguchi Factorial Design.

\begin{tabular}{ccc}
\hline Trial & \multicolumn{2}{c}{ Coded levels } \\
\cline { 2 - 3 } Number & HMWCH (1) & HPMC K15M (2) \\
\hline 1 & -1 & -1 \\
2 & -1 & 0 \\
3 & -1 & +1 \\
4 & 0 & -1 \\
5 & 0 & 0 \\
6 & 0 & +1 \\
7 & +1 & -1 \\
8 & +1 & 0 \\
9 & +1 & +1 \\
\hline
\end{tabular}

Table 3: Design Summary using Taguchi Design.

\begin{tabular}{cc}
\hline Taguchi Array & L9( $\left.3^{\wedge} 2\right)$ \\
Factors & 2 \\
Runs & 9 \\
\hline
\end{tabular}

Table 5: Factor Composition using 3 (2) Taguchi Factorial Design.

\begin{tabular}{cccc}
\hline Trial & \multicolumn{3}{c}{ Coded levels } \\
\cline { 2 - 4 } Number & HMWCH (A) & CPR (B) & HPMC K15M (C) \\
\hline 1 & -1 & -1 & -1 \\
2 & -1 & 0 & 0 \\
3 & -1 & +1 & +1 \\
4 & 0 & -1 & 0 \\
5 & 0 & 0 & +1 \\
6 & 0 & +1 & -1 \\
7 & +1 & -1 & +1 \\
8 & +1 & 0 & -1 \\
9 & +1 & +1 & 0 \\
\hline
\end{tabular}

different formulations was transferred in dissolution vessel containing $0.1 \mathrm{M} \mathrm{HCl}$ having temperature $37 \pm 0.5^{\circ} \mathrm{C}$ and rotated at $50 \mathrm{rpm}$. After specified interval of time (0 hours, 2 hours, 4 hours and six hours) the dialysis bag was removed from the vessel and outer water was completely dried with the help of filter paper, the precaution taken in to account that during drying stage there should be no any extra pressure is applied on the bag so that inside moisture comes outside and affects the result and accurately measured on digital balance (Verma et al., 2017).

\section{In vitro release studies and drug release kinetics}

Prepared HBS capsule containing formulations were immersed in $900 \mathrm{ml}$ of $0.1 \mathrm{M} \mathrm{HCl}$ and in vitro drug release from the prepared formulations in $0.1 \mathrm{M} \mathrm{HCl}(\mathrm{pH} 1.2)$ using USP XXIV type II (paddle type) apparatus (Electrolab; TDT-08L, Mumbai; India) at $50 \mathrm{rpm}$. Aliquots of $1 \mathrm{ml}$ of sample were withdrawn with the help of syringe fitted with $0.45 \mu \mathrm{m}$ membrane filter for analysis and an equal amount of fresh $0.1 \mathrm{M} \mathrm{HCl}$ was replaced in the dissolution
Table 2: Coded level translation in actual units.

\begin{tabular}{cccc}
\hline Coded Level & $\mathbf{- 1}$ & $\mathbf{0}$ & $\mathbf{+ 1}$ \\
\hline HMWCH $(\mathrm{mg})^{*}$ & 37.50 & 0.00 & 75.00 \\
HPMC K15M (mg) & 37.50 & 0.00 & 75.00 \\
\hline${ }^{*}$ Low, Medium and High coded translational levels of polymers were \\
chosen on the basis of trials study of experimental studies conducted for \\
efficient buoyancy and retardation of drug release.
\end{tabular}

Table 4: Optimized formulation composition of PRX with HPMC K15M, HMWCH and CPR

\begin{tabular}{ccccc}
\hline $\begin{array}{c}\text { Formulation } \\
\text { code }\end{array}$ & $\begin{array}{c}\text { PRX } \\
\text { (mg) }\end{array}$ & $\begin{array}{c}\text { HPMC } \\
\text { K15M (mg) }\end{array}$ & $\begin{array}{c}\text { HMWCH } \\
\text { (mg) }\end{array}$ & $\begin{array}{c}\text { CPR } \\
\text { (mg) }\end{array}$ \\
\hline S 1 & 20 & 37.50 & 37.50 & 75.00 \\
S 2 & 20 & 37.50 & 0.00 & 75.00 \\
S 3 & 20 & 37.50 & 75.00 & 75.00 \\
S 4 & 20 & 0.00 & 37.50 & 75.00 \\
S 5 & 20 & 0.00 & 0.00 & 75.00 \\
S 6 & 20 & 0.00 & 75.00 & 75.00 \\
S 7 & 20 & 75.00 & 37.50 & 75.00 \\
S 8 & 20 & 75.00 & 0.00 & 75.00 \\
S 9 & 20 & 75.00 & 75.00 & 75.00 \\
\hline
\end{tabular}

${ }^{*}$ Concentration of all the polymers were chosen on the basis of trials study of experimental studies conducted for efficient buoyancy and retardation of drug release. PRX: Piroxicam, HPMC K15M:

Hydroxypropyl Methylcellulose, HMWCH: High Molecular Weight Chitosan, CPR: Crushed Puffed Rice.

Table 6: Coded level translation in actual units.

\begin{tabular}{cccc}
\hline Coded Level & $\mathbf{- 1}$ & $\mathbf{0}$ & $\mathbf{+ 1}$ \\
\hline HMWCH $(\mathrm{mg})^{*}$ & 37.50 & 0 & 75.00 \\
HPMC K15M (mg) $^{*}$ & 37.50 & 0 & 75.00 \\
CPR $(\mathrm{mg})^{*}$ & 40.00 & 60.00 & 80.00 \\
\hline
\end{tabular}

${ }^{*}$ Concentration of all the polymers were chosen on the basis of initial trials of experimental study conducted for efficient buoyancy and retardation of drug release.

vessel. Obtained samples were analyzed for their absorbance at $333 \mathrm{~nm}$.

In order to explain the mechanism of drug release from the formulation, equations are used like Zero Order First Order, Higuchi model, and Korsmeyer- Peppas. Dosages form which follows zero order kinetics provides maximum therapeutic response with minimum side effects (Soni et al., 2017a; Verma et al., 2012).

First order release explains the initial amount of drug releases rapidly followed by sustaining the release in plasma. Such type of systems in plasma leads to fluctuation of drug and not maintains the plasma drug concentration profile uniformly.

Higuchi mechanism of drug release relates the drug release from the matrix system by the diffusion which is given by following equation:

$$
Q=K \sqrt{ } \mathbf{t} \ldots \text { (1) }
$$

Where $Q$ is the cumulative amount of drug release from the polymeric matrixes after coming to the dissolution medium in time $t$ and $\mathrm{K}$ is the release rate constant. 
Table 7: Design Summary using Taguchi Design.

\begin{tabular}{cc}
\hline Taguchi Array & $\mathrm{L} 9\left(3^{\wedge} 2\right)$ \\
Factors & 2 \\
Runs & 9 \\
\hline
\end{tabular}

Table 8: Optimized formulation composition of PRX with HPMC K15M, HMWCH and CPR.

\begin{tabular}{ccccc}
\hline $\begin{array}{c}\text { Formulation } \\
\text { code }\end{array}$ & $\begin{array}{c}\text { PRX } \\
\text { (mg) }\end{array}$ & $\begin{array}{c}\text { HPMC K15M } \\
\text { (mg)* }\end{array}$ & $\begin{array}{c}\text { HMWCH } \\
\text { (mg)* }\end{array}$ & $\begin{array}{c}\text { CPR } \\
\text { (mg)* }\end{array}$ \\
\hline T 1 & 20 & 37.50 & 37.50 & 40.00 \\
T 2 & 20 & 0 & 37.50 & 60.00 \\
T 3 & 20 & 75.00 & 37.50 & 80.00 \\
T 4 & 20 & 0 & 0 & 40.00 \\
T 5 & 20 & 75.00 & 0 & 60.00 \\
T 6 & 20 & 37.50 & 0 & 80.00 \\
T 7 & 20 & 75.00 & 75.00 & 40.00 \\
T 8 & 20 & 37.50 & 75.00 & 60.00 \\
T 9 & 20 & 0 & 75.00 & 80.00 \\
\hline
\end{tabular}

*Concentration of all the polymers were chosen on the basis of trials study of experimental studies conducted for efficient buoyancy and retardation of drug release. PRX: Piroxicam, HPMC K15M: Hydroxypropyl Methylcellulose, HMWCH: High Molecular Weight Chitosan, CPR: Crushed Puffed Rice.

Table 9: Formulation parameters for PRX-loaded HBS capsules prepared as Taguchi 3(2) factorial designs for formulations S1-S9.

\begin{tabular}{ccc}
\hline $\begin{array}{c}\text { Formulation } \\
\text { code }\end{array}$ & $\begin{array}{c}\text { Buoyancy }\left(\mathbf{Y}_{\mathbf{1}}\right) \\
\text { (Hours) }\end{array}$ & $\begin{array}{c}\mathbf{T}_{60 \%}\left(\mathbf{Y}_{\mathbf{2}}\right) \\
\text { (Hours) }\end{array}$ \\
\hline S 1 $(-1,-1)$ & 6.0 & 4.0 \\
S 2 $(-1,0)$ & 4.0 & 3.0 \\
S 3 $(-1,+1)$ & 4.5 & 5.5 \\
S 4 (0, -1) & 5.0 & 3.5 \\
S 5 $(0,0)$ & 3.0 & 3.0 \\
S 6 (0, +1) & 6.0 & 4.5 \\
S 7 (+1, -1) & 5.5 & 4.0 \\
S 8 (+1, 0) & 6.5 & 5.0 \\
S 9 (+1, +1) & 8.0 & 6.0 \\
\hline
\end{tabular}

Apart from this, Korsmeyer-Peppas equation was also used to investigate mechanism of drug release takes place from the swollen polymeric matrices which is given by following equation:

$$
M t / M \infty=t^{n} \ldots \text { (2) }
$$

Where $\mathrm{Mt} / \mathrm{M} \infty$ is the fraction of drug released in time $t$ and $\mathrm{K}$ is the structural and geometrical constant of dosages form, and $n$, is the release exponent. If the value of $n=0.5$, it explains Fickian diffusion mechanism of drug release, if it $0.5<\mathrm{n}<1.0$, the release it explains non Fickian diffusion and diffusion mechanism of drug release if $n=1.0$ and more than 1.0 it explains super case II transport of drug release.

Korsmeyer Peppas equation explains the mechanism of drug release by combination effect of diffusion and relaxation of polymeric strands after coming to the dissolution medium $(0.1 \mathrm{M} \mathrm{HCl})$. Apart from $\mathrm{r}^{2}$ value, (AIC)
Akaike Information Criteria was also used to authenticate the release kinetics value. AIC value was calculated by KinetDS-3.0 software by using following equation:

$$
\mathrm{AIC}=\mathrm{n}^{*} \text { In (WSSR) }+2^{*} \text { p... (3) }
$$

Where $\mathrm{n}$ is the number of dissolution sample points, $\mathrm{p}$ is the numbers of parameters of the model and WSSR is the weighed sum square. When compared with the several models from a given set of data, the model which has the lowest AIC value is considered as a best-fit model. All the models are applicable to the first $60 \%$ drug release (T60\%) from the polymeric matrices (Soni et al., 2016; Soni et al., 2017; Soni et al., 2017a).

\section{Statistical optimization and analysis of data}

Response surface methodology (RSM) computations for the optimization study were studied by using the Minitab18 software. Second-order statistical model, including polynomial equations, consist of independent variables and their interactions for various measured responses. The general form of the model is shown by following equation

$Y=\beta_{0}+\beta_{1} A+\beta_{2} B+\beta_{3} A B+\beta_{4} A^{2}+\beta_{5} B^{2}+\beta_{6} A^{2} \mathbf{B}+\beta_{7} \mathbf{A B}^{2}+$ $\beta_{8} A^{2} B^{2} \ldots \ldots$ (4)

Where $\beta_{0}$ is the intercept and it is arithmetic means of all the quantitative outcomes of nine experimental runs, $\beta_{1-}-\beta 8$ is the regression coefficients computed from the observed experimental values of $Y_{1}$ using software; $A$ and $B$ are the coded levels of independent variables; $A B$ is interaction between variables; $\mathrm{A}^{2}$ and $\mathrm{B}^{2}$ are polynomial terms. The main effect $A$ and $B$ symbolizes the average result of changing one factor at a time from low level value to high level value. The polynomial equation was used as interpretation tool and also used to draw a conclusion after considering the intensity of coefficient from mathematical sign it carries which may be positive or negative (high level to low level or low level to high level). The positive sign represents the synergistic action. One-way ANOVA provided in Minitab18 was used for statistical validity of the hypothesized model. Significance level was considered at $p<0.05$ (Kumar et al., 2015).

\section{RESULTS AND DISCUSSION}

In vitro stability studies of PRX in $0.1 \mathrm{M} \mathrm{HCl}$

PRX shows some degradation in $0.1 \mathrm{M} \mathrm{HCl}(\mathrm{pH} 1.2)$ in the concentration of $1 \mathrm{mg} / \mathrm{ml}, 3 \mathrm{mg} / \mathrm{ml}$ and $5 \mathrm{mg} / \mathrm{ml}$ but the degradation was not significantly found $(p>0.05)$. In the concentration of $1 \mathrm{mg} / \mathrm{ml} 0.04 \%$ of PRX degraded in $0.1 \mathrm{M}$ $\mathrm{HCl}$, whereas in concentration of $3 \mathrm{mg} / \mathrm{ml}$ and $5 \mathrm{mg} / \mathrm{ml}$ around $0.05 \%$ and $0.02 \%$ degradation takes place in acidic dissolution medium. These values are statistically not significant $(p>0.05)$. Degradation of the drug was not observed concentration dependent. It is believed that due to the formation of hydrogel polymeric structure after interaction in dissolution media $(0.1 \mathrm{M} \mathrm{HCl})$ it directly prevents the PRX from the degradation. This assures the PRX will be stable throughout the period of drug release in acidic medium (Soni et al., 2016).

\section{Drug Excipient interaction studies by}

(a) Functional group characterization of drug, excipient and drug excipient physical mixtures by using Fourier Transform Infrared spectroscopy (FTIR) studies

FTIR spectra of pure PRX (Figure 2a), observed at 3338.07 $\mathrm{cm}^{-1}$ which indicate that the PRX is in the polymorphic form. Spectra observed at $772.65 \mathrm{~cm}^{-1}, 1148.91 \mathrm{~cm}^{-1}, 1350.55 \mathrm{~cm}^{-1}$, $1435 \mathrm{~cm}^{-1}$ and $1629.84 \mathrm{~cm}^{-1}$ represent stretching of ortho-disubstituted phenyl, stretching of $-\mathrm{SO}_{2}-\mathrm{N}$ - group, stretching of the symmetric methyl group, asymmetric methyl group and amide carbonyl respectively. FTIR spectra of HPMC 
Table 10: Results of ANOVA for measured responses for formulations S1-S9.

\begin{tabular}{|c|c|c|c|c|c|}
\hline Parameter & SS & df & MS & $\mathbf{F}$ & Sgnificance $\mathbf{F}$ \\
\hline \multicolumn{6}{|c|}{ Buoyancy Time $\left(\mathrm{Y}_{1}\right)$} \\
\hline Model & 22.7869 & 5 & 6.9875 & 24.56 & 0.012 \\
\hline Residual & 0.5056 & 3 & 0.2013 & - & - \\
\hline Cor. total & 23.2925 & 8 & - & - & - \\
\hline \multicolumn{6}{|c|}{$R^{2}=0.986$; adj: 0.943} \\
\hline \multicolumn{6}{|c|}{ T60\% $\left(Y_{2}\right)$} \\
\hline Model & 15.9888 & 5 & 2.7655 & 17.89 & 0.019 \\
\hline Residual & 0.45557 & 3 & 0.15816 & - & - \\
\hline Cor. total & 16.4445 & 8 & - & - & - \\
\hline \multicolumn{6}{|c|}{$R^{2}=0.965 ;$ adj: 0.906} \\
\hline
\end{tabular}

df: Degree of freedom, SS: Sum of square, MS: Mean Square, F: Fischer's value.

K15M (Figure 2b) represents the stretching of alcohol C-O group at $1056.37 \mathrm{~cm}^{-1}$, absorption band at $1315.64 \mathrm{~cm}^{-1}$ represents stretching of $\mathrm{C}$-O- ether linkage. It also shows the stretching of alkyl C-H and phenolic O-H at $2932 \mathrm{~cm}^{-1}$ and $3466.89 \mathrm{~cm}^{-1}$ respectively (Soni et al., 2016).

FTIR spectra of (Figure $3 \mathrm{c}$ ) HMWCH shows the $\mathrm{C}-\mathrm{H}$ (aliphatic) stretching absorption band at $2920 \mathrm{~cm}^{-1}, \mathrm{O}-\mathrm{H}$ (phenolic) stretching at $3290 \mathrm{~cm}^{-1}, \mathrm{CH}_{2}$ (aliphatic) stretching at $1384 \mathrm{~cm}^{-1}, \mathrm{C}-\mathrm{O}-\mathrm{C}$ (ether linkage) $1151 \mathrm{~cm}^{-1}$ and N-H (I) overtone at 3500-3300 $\mathrm{cm}^{-1}$ (Soni et al., 2016). FTIR spectra of (Figure $3 \mathrm{~d}$ ) CPR absorption band observed at the peak $3403.46 \mathrm{~cm}^{-1}$ which represents to the alcohol $(\mathrm{O}-\mathrm{H})$ stretching having strong and broad absorption intensity peak. Sharp and broad peak intensity at $2927.16 \mathrm{~cm}^{-1}$ represents to the $\mathrm{CH}_{2}$ deformation having medium absorption peak. Broad and sharp peak intensity at $1649.58 \mathrm{~cm}^{-1}$ represents to the alkene $(\mathrm{C}=\mathrm{C})$ having medium peak intensity and also represents the tightly bound water adsorbed in the region of starch which was reported by (Santha et al., 1990; Wilson et al., 1991). Absorption peak intensity at $1412.57 \mathrm{~cm}^{-1}$ corresponds the $\mathrm{C}-\mathrm{O}-\mathrm{O}$ stretching and $\mathrm{CH}_{2}$ bending. Peak intensity at $1380.21 \mathrm{~cm}^{-1}$ shows the $\mathrm{C}-\mathrm{O}-\mathrm{H}$ bending, $\mathrm{CH}_{2}-$ twisting. Small absorption peak intensity at $1241.86 \mathrm{~cm}^{-1}$ represents the $\mathrm{CH}_{2} \mathrm{OH}$ (side chain) related mode. Broad and sharp peak intensity at $1156.98 \mathrm{~cm}^{-1}$ corresponds C-O, C-C stretching mode, whereas, the absorption peak intensity at $1085.85 \mathrm{~cm}^{-1}$ represents $\mathrm{C}-\mathrm{O}-\mathrm{H}$ bending and the absorption peak intensity at $1022.02 \mathrm{~cm}^{-1}$ and $931.48 \mathrm{~cm}^{-1}$ represents anhydro-glucose ring at $\mathrm{O}-\mathrm{C}$ stretching. In FTIR spectrum below $800 \mathrm{~cm}^{-1}$ correspond complex vibrational modes due to the skeletal mode vibrations of the pyranose ring in the glucose ring structure (Kizil et al., 2002; Huang et al., 2007). All investigated peaks are present in the parent peaks of starch as investigated and reported by (Kizil et al., 2002; Huang et al., 2007; Santha et al., 1990); since we are using CPR as a novel polymer for drug delivery this CPR also contains starch as its main constituent. From this FTIR study we can say that the basic constituent present in CPR is starch on the preliminary basis (Soni et al., 2017a).

In FTIR spectra of PRX (Figure 4 e) shows an absorption band at $3338.07 \mathrm{~cm}^{-1}$ which indicate that the PRX is in the polymorphic form. The absorption peak observed at $772.65 \mathrm{~cm}^{-1}, 1148.91 \mathrm{~cm}^{-1}, 1350.55 \mathrm{~cm}^{-1}, 1435 \mathrm{~cm}^{-1}, 1629.84$ $\mathrm{cm}^{-1}$ correspond to stretching of ortho-di-substituted phenyl, stretching of $-\mathrm{SO}_{2}-\mathrm{N}$ - group, stretching of the symmetric and asymmetric methyl group, carbonyl amide group respectively. It also shows absorption bands of C-O alcohol group stretching at $1297.12 \mathrm{~cm}^{-1}, \mathrm{C}-\mathrm{H}$ stretching absorption band of alkane group observed at $2887.98 \mathrm{~cm}^{-1}$, alcoholic $\mathrm{O}-\mathrm{H}$ stretching absorption band observed at $3678.18 \mathrm{~cm}^{-1}$, and (ether linkage) C-O absorption band observed at $1211.40 \mathrm{~cm}^{-1}$. It has also the characteristics peaks of CPR (figure $3 \mathrm{~d}$ ) like C-O stretching (alcohol) at 1143.29 $\mathrm{cm}^{-1}$, and $\mathrm{O}-\mathrm{H}$ stretching (alcohol) absorption band observed at $3619.31 \mathrm{~cm}^{-1}$ and $\mathrm{C}-\mathrm{O}$ stretching of (ether) absorption band observed at $1112.17 \mathrm{~cm}^{-1}$. From this we can say that there is no any interaction takes place between PRX, HPMCK15M and CPR.

In the spectra (Figure $4 \mathrm{f}$ ) shows the absorption band of alcoholic C-O stretching observed at $1177.67 \mathrm{~cm}^{-1}$, ketonic $\mathrm{C}=\mathrm{O}$ stretching observed at $1706.46 \mathrm{~cm}^{-1}$, alcoholic $\mathrm{O}$ $\mathrm{H}$ stretching observed at $3648.66 \mathrm{~cm}^{-1}$, sulfoxide $(\mathrm{S}=\mathrm{O})$ stretching observed at $1031.97 \mathrm{~cm}^{-1}$, amines (C-N) stretching observed at $1345.76 \mathrm{~cm}^{-1}$, secondary amines $\mathrm{N}-\mathrm{H}$ stretching absorption band observed at $3678.25 \mathrm{~cm}^{-1}$, aromatic $C=C$ stretching observed at $1528.87 \mathrm{~cm}^{-1}$ aromatic $C$ $\mathrm{H}$ stretching observed at $3332.27 \mathrm{~cm}^{-1}$, besides these it also shows the characteristics absorption bands of alcoholic C$\mathrm{O}$ stretching observed at $1143.88 \mathrm{~cm}^{-1}$, alcoholic O-H stretching observed at $3619.73 \mathrm{~cm}^{-1}$, amines C-N stretching observed at $1297.16 \mathrm{~cm}^{-1}$, ether C-O stretching observed at $1113.04 \mathrm{~cm}^{-1}$, secondary amines $\mathrm{N}-\mathrm{H}$ stretching frequency observed at $3565.58 \mathrm{~cm}^{-1}$. It has characteristics absorption peaks of CPR, alcoholic C-O stretching observed at 1211.86 $\mathrm{cm}^{-1}$, alcoholic O-H stretching observed at $3829.59 \mathrm{~cm}^{-1}$ and ether C-O stretching observed at $1087.05 \mathrm{~cm}^{-1}$. All these characteristics peaks are present in PRX, HMWCH and $\mathrm{CPR}$ and there is no any deviation of absorption peaks from parent peaks from this we can divulge that there is no any drug excipient interaction occurs.

Table 11: Formulation parameters for PRX-loaded HBS capsules prepared as Taguchi 3 (2) factorial designs for T1-T9.

\begin{tabular}{ccc}
\hline $\begin{array}{c}\text { Formulation } \\
\text { code }\end{array}$ & $\begin{array}{c}\text { Buoyancy }\left(\mathbf{Y}_{\mathbf{1}}\right) \\
\text { (Hours) }\end{array}$ & $\begin{array}{c}\left.\mathbf{T}_{60} \mathbf{( Y}_{\mathbf{2}}\right) \\
\text { (Hours) }\end{array}$ \\
\hline T 1 $(-1,-1,-1)$ & 7.0 & 4.0 \\
T 2 $(-1,0,0)$ & 7.0 & 4.5 \\
T 3 $(-1,1,1)$ & 8.0 & 6.5 \\
T 4 $(0,-1,0)$ & 7.5 & 5.5 \\
T 5 $(0,0,1)$ & 6.0 & 4.0 \\
T 6 $(0,1,-1)$ & 6.5 & 4.5 \\
T 7 $(1,-1,1)$ & 7.5 & 6.0 \\
T 8 $(1,0,-1)$ & 7.0 & 5.5 \\
T 9 $(1,1,0)$ & 8.0 & 6.0 \\
\hline
\end{tabular}


Table 12: Results of ANOVA for measured responses for formulations T1-T9.

\begin{tabular}{|c|c|c|c|c|c|}
\hline Parameter & SS & df & MS & $\mathbf{F}$ & Sgnificance F \\
\hline \multicolumn{6}{|c|}{ Buoyancy Time $\left(\mathrm{Y}_{1}\right)$} \\
\hline Model & 23.1809 & 5 & 5.8855 & 20.56 & 0.016 \\
\hline Residual & 0.4056 & 3 & 0.2032 & - & - \\
\hline Cor. total & 23.5865 & 8 & - & - & - \\
\hline \multicolumn{6}{|c|}{$\mathrm{R}^{2}=0.978$; adj: 0.945} \\
\hline \multicolumn{6}{|c|}{$\mathrm{T} 60 \%\left(\mathrm{Y}_{2}\right)$} \\
\hline Model & 14.7898 & 5 & 2.1605 & 17.89 & 0.011 \\
\hline Residual & 0.55557 & 3 & 0.1786 & - & - \\
\hline Cor. total & 15.3453 & 8 & - & - & - \\
\hline \multicolumn{6}{|c|}{$\mathrm{R}^{2}=0.965 ;$ adj: 0.924} \\
\hline
\end{tabular}

Table 13: In vitro buoyancy studies and \% Drug concentration determination.

\begin{tabular}{|c|c|c|c|c|}
\hline $\begin{array}{l}\text { Formulation } \\
\text { code }\end{array}$ & $\begin{array}{l}\text { Floating lag } \\
\text { time (Sec) }\end{array}$ & $\begin{array}{l}\text { Buoyancy time } \\
\text { (Hr) }\end{array}$ & $\begin{array}{l}\text { \% Drug concentra- } \\
\text { tion uniformity* }\end{array}$ & Comments \\
\hline S1 & Nil & Buoyant for $6.0 \mathrm{hr}$ & $99.91 \pm 1.01$ & $\begin{array}{l}\text { Remained buoyant for } 6.0 \mathrm{hr} \text { as an irregular polymeric raft. } \\
\text { Drug release was found to be erratic. }\end{array}$ \\
\hline S2 & Nil & Buoyant for $4.0 \mathrm{hr}$ & $98.09 \pm 1.03$ & $\begin{array}{l}\text { Remained buoyant for } 4 \mathrm{hr} \text {. Acquired the shape of a cylindrical } \\
\text { gel. Drug release was retarded up to } 4.0 \mathrm{hr}\end{array}$ \\
\hline S3 & Nil & Buoyant for $4.5 \mathrm{hr}$ & $98.87 \pm 1.04$ & $\begin{array}{l}\text { Formulation sank after } 4.5 \mathrm{hr} \text {. Acquired the shape of plug shape } \\
\text { matrix. Drug release was retarded up to } 06 \mathrm{hr} \text {. }\end{array}$ \\
\hline S4 & Nil & Buoyant for $5.0 \mathrm{hr}$ & $98.16 \pm 1.21$ & $\begin{array}{l}\text { Formulation sank after } 3.5 \mathrm{hr} \text {. Acquired the shape of polymeric } \\
\text { slab. Drug release was retarded up to } 05 \mathrm{hr} \text {. }\end{array}$ \\
\hline S5 & Nil & Buoyant for $3.0 \mathrm{hr}$ & $98.11 \pm 1.13$ & $\begin{array}{l}\text { Remained buoyant up to } 3 \mathrm{hr} \text {. Acquired the shape of irregular } \\
\text { gel matrix. Drug release was retarded up to } 03 \mathrm{hr} \text {. }\end{array}$ \\
\hline S6 & Nil & Buoyant for $6.0 \mathrm{hr}$ & $99.22 \pm 1.02$ & $\begin{array}{l}\text { Remained buoyant up to } 4.5 \mathrm{hr} \text {. Acquired the shape of irregular } \\
\text { gel matrix. Drug release was retarded up to } 4.5 \mathrm{hr} \text {. }\end{array}$ \\
\hline S7 & Nil & Buoyant for $5.5 \mathrm{hr}$ & $98.19 \pm 1.31$ & $\begin{array}{l}\text { Remained buoyant up to } 5.5 \mathrm{hr} \text {. Acquired the shape of cylindri- } \\
\text { cal matrix. Drug release was retarded. }\end{array}$ \\
\hline S8 & Nil & Buoyant for $6.5 \mathrm{hr}$ & $98.15 \pm 1.23$ & $\begin{array}{l}\text { Remained buoyant up to } 6.5 \mathrm{hr} \text {. Acquired the shape of cylindri- } \\
\text { cal matrix. Drug release was retarded up to } 6.5 \mathrm{hr} \text {. }\end{array}$ \\
\hline S9 & Nil & Buoyant for $8.0 \mathrm{hr}$ & $99.38 \pm 1.18$ & $\begin{array}{l}\text { Remained buoyant up to } 8 \mathrm{hr} \text {. Acquired the shape of cylindrical } \\
\text { matrix. Drug release was retarded up to } 08 \mathrm{hr} \text {. }\end{array}$ \\
\hline
\end{tabular}

${ }^{*}$ All determinations were carried out in triplicate, mean $\pm S D$.

Table 14: In vitro buoyancy studies and $\%$ Drug concentration determination.

\begin{tabular}{|c|c|c|c|c|}
\hline $\begin{array}{l}\text { Formula- } \\
\text { tion code }\end{array}$ & $\begin{array}{l}\text { Floating lag } \\
\text { time (Sec) }\end{array}$ & $\begin{array}{l}\text { Buoyancy time } \\
\text { (Hr) }\end{array}$ & $\begin{array}{l}\text { \% Drug concentra- } \\
\text { tion uniformity* }\end{array}$ & Comments \\
\hline T1 & Nil & Buoyant for $7.0 \mathrm{hr}$ & $97.91 \pm 1.00$ & $\begin{array}{l}\text { Remained buoyant for } 7 \mathrm{hr} \text { as an irregular raft after the dissolu- } \\
\text { tion of capsule shell. Hydrogel structure developed. }\end{array}$ \\
\hline $\mathrm{T} 2$ & Nil & Buoyant for $7.0 \mathrm{hr}$ & $97.19 \pm 1.04$ & $\begin{array}{l}\text { Remained buoyant for } 7 \mathrm{hr} \text {. Acquired the shape of a slab. Drug } \\
\text { release was retarded up to period of } 07 \mathrm{hr} \text {. }\end{array}$ \\
\hline T3 & Nil & Buoyant for $8.0 \mathrm{hr}$ & $99.25 \pm 1.05$ & $\begin{array}{l}\text { Remained buoyant for } 08 \mathrm{hr} \text {. Acquired the shape of irregular cy- } \\
\text { lindrical matrix. Drug release of PRX was retarded up to } 8 \mathrm{hr} \text {. }\end{array}$ \\
\hline $\mathrm{T} 4$ & Nil & Buoyant for $7.5 \mathrm{hr}$ & $98.06 \pm 1.06$ & $\begin{array}{l}\text { Formulation sank after } 7.5 \mathrm{hr} \text {. Acquired the shape of cylindrical } \\
\text { matrix. Drug release was retarded up to } 7.5 \mathrm{hr} \text {. }\end{array}$ \\
\hline T5 & Nil & Buoyant for $6.0 \mathrm{hr}$ & $97.91 \pm 1.23$ & $\begin{array}{l}\text { Remained buoyant up to } 6 \mathrm{hr} \text {. Formulation acquired the shape } \\
\text { of plug shape. Drug release was retarded up to } 06 \mathrm{hr} \text {. }\end{array}$ \\
\hline T6 & Nil & Buoyant for $6.5 \mathrm{hr}$ & $96.22 \pm 1.20$ & $\begin{array}{l}\text { Remained buoyant up to } 6.5 \mathrm{hr} \text {. Formulation acquired the shape } \\
\text { of cylindrical matrix. Drug release was retarded up to } 7 \mathrm{hr} \text {. }\end{array}$ \\
\hline T7 & Nil & Buoyant for $7.5 \mathrm{hr}$ & $99.09 \pm 1.01$ & $\begin{array}{l}\text { Remained buoyant for } 7.5 \mathrm{hr} \text {. Formulation acquired the shape of } \\
\text { cylindrical matrix. Drug release was retarded for } 7.5 \mathrm{hr} \text {. }\end{array}$ \\
\hline T8 & Nil & Buoyant for $7.0 \mathrm{hr}$ & $98.98 \pm 1.73$ & $\begin{array}{l}\text { Remained buoyant up to } 7 \mathrm{hr} \text {. Formulation acquired the shape } \\
\text { of cylindrical matrix. Drug release was retarded up to } 07 \mathrm{hr} \text {. }\end{array}$ \\
\hline T9 & Nil & Buoyant for $8.0 \mathrm{hr}$ & $98.08 \pm 1.32$ & $\begin{array}{l}\text { Remained buoyant up to } 8 \mathrm{hr} \text {. Formulation acquired the shape } \\
\text { of cylindrical matrix. Drug release was retarded up to } 09 \mathrm{hr} \text {. }\end{array}$ \\
\hline
\end{tabular}


Table 15: Drug release kinetics and AIC value determination; determined for amount of drug releases up to $60 \%$ (T $60 \%$ ).

\begin{tabular}{|c|c|c|c|c|c|c|c|c|c|}
\hline \multirow[b]{2}{*}{ F. Code } & \multicolumn{4}{|c|}{$\mathbf{r}^{2}$} & \multirow[b]{2}{*}{ n-Value } & \multicolumn{3}{|c|}{ AIC Value } & \multirow[b]{2}{*}{ Comments } \\
\hline & $\begin{array}{l}\text { Zero } \\
\text { Order }\end{array}$ & $\begin{array}{c}\text { First } \\
\text { Order }\end{array}$ & $\begin{array}{c}\text { Higuchi } \\
\text { model }\end{array}$ & $\begin{array}{c}\text { Korsmeyer- } \\
\text { Peppas }\end{array}$ & & $\begin{array}{l}\text { Zero } \\
\text { Order }\end{array}$ & $\begin{array}{l}\text { First } \\
\text { Order }\end{array}$ & $\begin{array}{c}\text { Higuchi } \\
\text { model }\end{array}$ & \\
\hline S1 & 0.9856 & 0.7934 & 0.9871 & 0.9130 & 0.44 & 33.41 & 43.23 & 54.90 & Zero order and Fickian diffusion \\
\hline S2 & 0.9897 & 0.9668 & 0.7149 & 0.9130 & 0.41 & 38.12 & 40.12 & 67.45 & Zero order and Fickian diffusion \\
\hline S3 & 0.9638 & 0.6570 & 0.8196 & 0.8186 & 0.45 & 37.12 & 78.12 & 67.51 & Zero order and Fickian diffusion \\
\hline S4 & 0.9967 & 0.9180 & 0.8689 & 0.9831 & 0.41 & 44.12 & 67.65 & 56.98 & Zero order and Fickian diffusion \\
\hline S5 & 0.9993 & 0.9831 & 0.8740 & 0.9623 & 0.43 & 34.87 & 44.12 & 67.87 & Zero order and Fickian diffusion \\
\hline S6 & 0.8995 & 0.8854 & 0.8933 & 0.8374 & 0.39 & 36.90 & 76.78 & 46.90 & Zero order and Fickian diffusion \\
\hline S7 & 0.9907 & 0.7394 & 0.8992 & 0.9864 & 0.44 & 39.23 & 47.78 & 45.67 & Zero order and Fickian diffusion \\
\hline S8 & 0.9895 & 0.9687 & 0.9568 & 0.9712 & 0.45 & 30.34 & 78.23 & 56.01 & Zero order and Fickian diffusion \\
\hline S9 & 0.9954 & 0.7897 & 0.9317 & 0.9814 & 0.43 & 33.87 & 62.23 & 98.56 & Zero order and Fickian diffusion \\
\hline
\end{tabular}

Table 16: Drug release kinetics and AIC value determination; determined for amount of drug release up to $60 \%$ (T60\%).

\begin{tabular}{|c|c|c|c|c|c|c|c|c|c|}
\hline \multirow[b]{2}{*}{ F. Code } & \multicolumn{4}{|c|}{$\mathbf{r}^{2}$} & \multirow[b]{2}{*}{ n -Value } & \multicolumn{3}{|c|}{ AIC Value } & \multirow[b]{2}{*}{ Comments } \\
\hline & $\begin{array}{l}\text { Zero } \\
\text { Order }\end{array}$ & $\begin{array}{l}\text { First } \\
\text { Order }\end{array}$ & $\begin{array}{c}\text { Higuchi } \\
\text { model }\end{array}$ & $\begin{array}{c}\text { Korsmeyer- } \\
\text { Peppas }\end{array}$ & & $\begin{array}{l}\text { Zero } \\
\text { Order }\end{array}$ & $\begin{array}{l}\text { First } \\
\text { Order }\end{array}$ & $\begin{array}{c}\text { Higuchi } \\
\text { model }\end{array}$ & \\
\hline T1 & 0.9876 & 0.6444 & 0.9871 & 0.9404 & 0.45 & 39.76 & 93.98 & 54.9 & Zero order and Fickian diffusion \\
\hline T2 & 0.9997 & 0.9768 & 0.7049 & 0.853 & 0.4 & 41.56 & 80.9 & 99.45 & Zero order and Fickian diffusion \\
\hline T3 & 0.9748 & 0.976 & 0.8196 & 0.8086 & 0.44 & 46.32 & 98.89 & 81.51 & Zero order and Fickian diffusion \\
\hline T4 & 0.9997 & 0.9676 & 0.8609 & 0.963 & 0.43 & 59.89 & 77.56 & 85.98 & Zero order and Fickian diffusion \\
\hline T5 & 0.9991 & 0.9791 & 0.9847 & 0.9529 & 0.42 & 56.89 & 84.87 & 99.87 & Zero order and Fickian diffusion \\
\hline T6 & 0.9979 & 0.8124 & 0.9933 & 0.9974 & 0.43 & 65.9 & 66.9 & 109.9 & Zero order and Fickian diffusion \\
\hline T7 & 0.9967 & 0.8964 & 0.879 & 0.9864 & 0.45 & 64.39 & 97.89 & 89.67 & Zero order and Fickian diffusion \\
\hline T8 & 0.9998 & 0.9027 & 0.8668 & 0.9123 & 0.44 & 50.67 & 68.89 & 78.01 & Zero order and Fickian diffusion \\
\hline T9 & 0.9994 & 0.8697 & 0.9007 & 0.9104 & 0.43 & 62.34 & 92.33 & 89.56 & Zero order and Fickian diffusion \\
\hline
\end{tabular}


(b) Thermo analytical Characterization of drug, polymers and physical mixtures

Figure 5 shows the thermal properties of PRX under experimental conditions. The DTG/TGA thermogram shows that the drug is stable up to $255^{\circ} \mathrm{C}$ and degradation of PRX is a one stage process. Maximum degradation of PRX and maximum loss of mass occurs at temperature between 250$300^{\circ} \mathrm{C}$ (approximate $60 \%$ ). The DTA thermogram of PRX shows one sharp endothermic peak at $201^{\circ} \mathrm{C}$ corresponding to the melting point of PRX whereas a broad exothermic peak at $259^{\circ} \mathrm{C}$ attributed to the slow degradation of PRX (Soni et al., 2016).

Figure 6 shows the thermal properties of HPMC $\mathrm{K} 15 \mathrm{M}$. The DTG thermogram shows the broad exothermic peak at $345^{\circ} \mathrm{C}$ and small exothermic peak at $499^{\circ} \mathrm{C}$. DTA exothermic peak at $355^{\circ} \mathrm{C}$ represents that the slow melting of the HPMC K15M and another exothermic peak at $505^{\circ} \mathrm{C}$ representing the degradation. Maximum loss of mass, $78.9 \%$ took place at temperature of $379^{\circ} \mathrm{C}$ and at $500^{\circ} \mathrm{C}$ up to $92 \%$ mass was loss under experimental condition. However, this thermogram also represents that the degradation of HPMC K15M is a two stage process one at a lower temperature and another at a higher temperature due to the presence of two groups (Soni et al., 2016).

Figure 7 shows the thermal properties of $\mathrm{HMWCH}$. The DTG thermogram shows the HMWCH is stable up to the temperature of $296^{\circ} \mathrm{C}$ whereas in the thermogram there is a very small exothermic peak at $73^{\circ} \mathrm{C}$ which represents the vaporization of water from $\mathrm{HMWCH}$ and the degradation of $\mathrm{HMWCH}$ is a one stage process. Degradation of $\mathrm{HMWCH}$ and maximum loss of mass occurs at temperature between $296-310^{\circ} \mathrm{C}$ (approximate 41\%). DTA thermogram of $\mathrm{HMWCH}$ represents one broad exothermic peak at $304^{\circ} \mathrm{C}$, which represents the slow degradation of the HMWCH (Soni et al., 2016).

Figure 8 represents the thermal properties of CPR under experimental condition. DTA shows endothermic peak at $288^{\circ} \mathrm{C}$ (enthalpy $25.9 \mathrm{~mJ} / \mathrm{mg}$ ) which represents the glass transition temperature of CPR. The exothermic peak at $499^{\circ} \mathrm{C}$ (enthalpy $-921 \mathrm{~mJ} / \mathrm{mg}$ ) and $636^{\circ} \mathrm{C}$ (enthalpy -1.05 $\mathrm{J} / \mathrm{mg}$ ) represents the slow degradation of CPR under experimental condition. DTG and TG thermogram represents the $\mathrm{CPR}$ is stable up to temperature of $290^{\circ} \mathrm{C}$, exothermic peak at $633^{\circ} \mathrm{C}$ represents the degradation of CPR and maximum loss of mass $41.6 \%$ occurs from temperature $253^{\circ} \mathrm{C}$ to $316^{\circ} \mathrm{C}$ and $4.7 \%$ loss of mass occurs at temperature $639^{\circ} \mathrm{C}$ (Soni et al., 2017a).

Figure 9 represents the thermal properties of PRX with HMWCH. DTG thermogram represents sharp exothermic peak at $255^{\circ} \mathrm{C}$ which explains that the drug is stable up to temperature $255^{\circ} \mathrm{C}$, second broad exothermic peak at $303^{\circ} \mathrm{C}$ explains that the polymer is stable up to temperature $303^{\circ} \mathrm{C}$. The maximum loss of mass takes place between $264^{\circ} \mathrm{C}-316^{\circ} \mathrm{C}$. DTA thermogram represents the one endothermic peak at $202^{\circ} \mathrm{C}$ and this peak present in the DTG curve of PRX (figure 5), exothermic peak at $308^{\circ} \mathrm{C}$ explains the slow degradation of drug and polymer used and this also explains that the there is no interaction occurs between PRX and HMWCH (Soni et al., 2016).

Figure 10 represents the thermal properties of PRX with HMWCH and HPMC K15M. DTG and TGA thermogram explains the formulation is stable up to the temperature $332^{\circ} \mathrm{C}$. In this loss of mass is biphasic process at the temperature of $250^{\circ} \mathrm{C}$ maximum loss of mass took place of $16.6 \%$ and at second stage at $332^{\circ} \mathrm{C}, 61.5 \%$ loss of mass occurs. DTG thermogram explains the formulation is stable up to temperature of $300^{\circ} \mathrm{C}$. DTA thermogram also explains that endothermic peak at $198^{\circ} \mathrm{C}$ which is of PRX melting peak whereas broad exothermic peak at $311^{\circ} \mathrm{C}$ is of slow degradation of PRX and polymers used (Soni et al., 2016).

Figure 11 represents the thermal properties of drug and polymers in combination. DTA thermogram represents the endothermic peak at $195^{\circ} \mathrm{C}$ (enthalpy $12.6 \mathrm{~mJ} / \mathrm{mg}$ ) of melting peak of PRX however this peak is shifted from $201{ }^{\circ} \mathrm{C}$, exothermic peak at $360^{\circ} \mathrm{C}$ (enthalpy $-378 \mathrm{~mJ} / \mathrm{mg}$ ), $612^{\circ} \mathrm{C}$ and $645^{\circ} \mathrm{C}$ (enthalpy $-2.66 \mathrm{~J} / \mathrm{mg}$ ) represents the slow degradation of $\mathrm{HMWCH}$, HPMC and CPR used. DTG thermogram represents these combinations of polymers are stable at temperature $335^{\circ} \mathrm{C}$, exothermic peak at $609^{\circ} \mathrm{C}$ represents the slow degradation. TG thermogram represents the biphasic curves the first curve from temperature 200$300^{\circ} \mathrm{C}$ maximum loss of mass occurs $59.56 \%$ and second curve from temperature $355-500^{\circ} \mathrm{C}$ loss of mass occurs $20.36 \%$. From this thermal characterization studies we can say that there is no drug excipient interaction takes place.

Effect of formulation variable on buoyancy $\left(Y_{1}\right)$ for formulations S1-S9

The constant and regression coefficients for $\mathrm{Y}_{1}$ (buoyancy time) depicted as following:

$Y_{1}=3.167+0.776 A+2.176 B+1.678 A * A+2.000 B * B+0.375 A * B$

The polynomial model was found significant with $F$ value of $24.56(p=0.012)$ [Table 10]. Above equation signifies that $\mathrm{AB}, \mathrm{A}^{2}, \mathrm{~B}^{2}$ were significant model terms. The combined effect of factors A and B [Figure 12 (a), (c) and 13 (e)] and from figure 12 (a) we can say that the high levels of HPMC $\mathrm{K} 15 \mathrm{M}$ and $\mathrm{HMWCH}$ is responsible for achieving buoyancy The desired effect is maximum at the high level $(+1)$ i.e. 6.68308 for HPMC K15M and 6.16474 for HMWCH. Figure 12 (c) represents the contour plot for buoyancy in which by adding the levels of HPMC K15M (+1) in HMWCH imparts buoyancy and contour area is also increasing from -1 to +1 level. The desired effect is maximum in buoyancy time $(>8$ hours) at high levels (+1) i.e. 0.934510 and lower in buoyancy time $(<3$ hours) at low levels i.e. -0.103552 . Figure 13 (e) reveals that by increasing the level of HPMC K15M in $\mathrm{HMWCH}$ the buoyancy time is increasing and this is attributed due to being entropy favored process the number of $\mathrm{H}^{+}$ions from dissolution media penetrated inside this causes the swelling and also entrapment of air which leads to lesser density than the utility and remained buoyant for prolonged period of time.

\section{Effect of formulation variable on $\mathrm{T} 60 \%$ drug release $\left(Y_{2}\right)$ for formulations S1-S9}

The constant and regression coefficients for $\mathrm{Y}_{2}$ ( $\mathrm{T} 60 \%$ drug release) depicted as following:

$Y_{2}=3.218+0.278 A+0.964 B+0.576 A * A+2.933 B * B+0.002 A * B$

The polynomial model was found significant with $F$ value of $17.89(p=0.019)$ [Table 10]. Above equation signifies that $\mathrm{AB}, \mathrm{A}^{2}, \mathrm{~B}^{2}$ were significant model terms. The combined effect of factor $A$ and $B$ is shown by [Figure $12(b, d)$ and Figure 13 (f)]. Figure 12 (b) represents the main effects plot for means for $\mathrm{T} 60 \%$ drug release and it shows the desired effect high at high levels (+1) of HPMC K15M and $\mathrm{HMWCH}$ i.e. 5.01214 and 5.32610 respectively. The high levels $(+1)$ are only responsible for holding the PRX in the polymeric matrixes for the longer period of time. The desired effect is high at higher levels for $\mathrm{HMWCH}$ as compared to HPMC K15M. Contour plot represented in figure 12 (d) from this graph we can clearly interpret that by increasing the levels (+1) of HPMC K15M and HMWCH the contour area is increasing which in turn mean that the retardation time for PRX release increases. Desired effect is 
maximum at PRX release $<6.0$ hours i.e. 0.999430 and minimum in PRX release $>3.0$ hours i.e. -0.334233 . Figure 13 (f) represents the wireframe graph which explains that the combination of HPMC K15M and HMWCH produces the synergistic effect and cumulative $\mathrm{T} 60 \%$ drug release rate extends to the period of time at high levels $(+1)$ for both the polymers.

\section{Effect of formulation variable on buoyancy $\left(Y_{1}\right)$ for formu- lations T1-T9}

The constant and regression coefficients for $\mathrm{Y}_{1}$ (buoyancy time) depicted as following:

\section{$Y_{1}=3.330+0.243 A+0.923 B+0.516 A * A+2.100 B * B+0.003 A * B$}

The polynomial model was found significant with $F$ value of $20.56(p=0.016)$ [Table 12]. Above equation signifies that $\mathrm{AB}, \mathrm{A}^{2}, \mathrm{~B}^{2}$ were significant model terms. Figure 13 (a) represents the role of each polymer used in terms of imparting buoyancy to the formulation. Above images reveal that at high levels $(+1)$ of polymers are responsible for imparting buoyancy to the formulation. The desired effect was found higher in CPR followed by HMWCH and HPMC K15M i.e. $7.78903,7.50366$ and 7.16585 respectively, which means that the CPR has the major role in imparting buoyancy in formulation T1-T9. Figure 13 (b) represents the main effects plot for means for $\mathrm{T} 60 \%$ drug release as increasing the levels $(-1$ to +1$)$ the retardation rate of PRX increases with respect to time. The desired effect is maximum in CPR followed by HMWCH and HPMC K15M i.e., 5.96203, 5.83397 and 5.50156 respectively. Above findings suggests that the $\mathrm{CPR}$ has the major role in imparting buoyancy and retardation of PRX from the biological macromolecules alone and in combination with auxiliary polymers. Figure 14 (a, b) represents the contour plot for formulation T1-T9 for HPMC K15M, CPR and HPMC K15M, HMWCH. The better buoyancy effect was observed in the formulation which has a combination of HPMC K15M, CPR rather than HPMC $\mathrm{K} 15 \mathrm{M}, \mathrm{HMWCH}$ as clearly indicated by contour plot that area is profoundly and smoothly increases but in case of combination with HPMC K15M, HMWCH the buoyancy was not significantly achieved when in combination use. Figure 15 (c, d) represents the surface plot it suggests that the high levels $(+1)$ of formulations are responsible achieving buoyancy and gastroretention.

\section{Effect of formulation variable on $\mathrm{T} 60 \%$ drug release $\left(Y_{2}\right)$ for formulations T1-T9}

The constant and regression coefficients for $\mathrm{Y}_{2}$ (T $60 \%$ drug release) for formulations T1-T9 depicted as following:

\section{$Y_{2}=3.110+0.360 A+0.917 B+0.491 A^{*} A+2.001 B * B+0.007 A^{*} B$}

The polynomial model was found significant with $F$ value of $17.89(p=0.011)$ [Table 12]. Above equation signifies that $A B, A^{2}, B^{2}$ were significant model terms. Figure $13(b)$ represents the main effects for means for $\mathrm{T} 60 \%$ drug release studies. It depicts that the increasing the levels of polymers from low level to high level $(-1$ to +1$)$ the retardation rate of PRX from matrixes decreases which are correlated with the desired effect value. For HPMC K15M desired effect value increases from -1 to +1 level i.e. 4.67055 and 5.50156 respectively. For $\mathrm{HMWCH}$ and $\mathrm{CPR}$ also desired effect value increases from low-level value to high-level value i.e. 5.00869 to 5.83397 and 5.16916 to 5.96203 respectively. The desired effect for $\mathrm{T} 60 \%$ drug release was maximum; 5.96203 in case of CPR used in formulation alone and in combination, so from this we can state that the CPR has the major role in retarding the release of PRX from the matrixes. Figure 14 (c and d) represents the contour plot for formulation $\mathrm{T} 1-\mathrm{T} 9$ for $\mathrm{T} 60 \%$ drug release in $0.1 \mathrm{M} \mathrm{HCl}$ which comprises a different blend of polymers with PRX. Figure
14 (c) represents the blends mixture of PRX with HPMC $\mathrm{K} 15 \mathrm{M}$ and $\mathrm{HMWCH}$ and figure $14(\mathrm{~d})$ represent the blends mixture of PRX with HPMC K15M and CPR after coming in $0.1 \mathrm{M} \mathrm{HCl} \mathrm{L}^{-1}$ dissolution media. The contour area is better in the formulation in which the HMWCH and CPR are used rather than the HPMC K15M and HMWCH on the basis of desired effect value. The desired effect value was significantly better in high levels $(+1)$ for the combination of HMWCH and CPR i.e. 0.758390 and HPMC K15M and $\mathrm{HMWCH}$ i.e. 0.691390 respectively. From this conducted study we can say that combination of polymers in which CPR has high levels $(+1)$ has pronounced more effect than any other auxiliary polymers used in the formulation. Figure 15 ( $a$ and $b$ ) represents the wireframe surface plot for both the sets of polymer HMWCH and CPR, HPMC K15M and $\mathrm{HMWCH}$ from this we can say that the high levels $(+1)$ of polymers are responsible for achieving retardation of PRX from the polymeric matrixes and sustaining the release of it follows by zero order kinetics.

\section{Drug Release Studies in $0.1 \mathrm{M} \mathrm{HCl}$}

The dissolution profile of the PRX loaded formulations filled in hard gelatin capsule shell of size 1, was performed under in vitro experimental condition $(0.1 \mathrm{M} \mathrm{HCl}$, USP apparatus II, temperature; $37 \pm 0.5^{\circ} \mathrm{C}, \mathrm{RPM} ; 50$ ) as represented in figure 16-19. In the present investigation, we have explored the potential of PRX loaded with HPMC K15M, $\mathrm{HMWCH}$, and $\mathrm{CPR}$ for sustaining the release rate in $0.1 \mathrm{M}$ $\mathrm{HCl}$ for stomach specific delivery. From the carried experimental studies, it was found that the erosion and disruption of the capsule shell begin as it comes in contact with dissolution media $(0.1 \mathrm{M} \mathrm{HCl})$. The average release profile time for all the formulation was found to be 10 hours and this is the rate-limiting step for the release retarding. As the dissolution media comes to contact with the polymeric system it forms glassy polymeric structures since the polymer used was hydrophilic and from these matrices the drug diffuse out slowly. In our case, there is large density difference between PRX, CPR, HPMC, and HMWCH used. PRX seems to be coated on the low-density HPMC, CPR and on Chitosan. When these formulations are exposed to the dissolution media, only the PRX adhered to the surface of the structure comes to the dissolution medium.

Durig et al., 2002 and Li et al., 2003 investigated the increase in viscosity results in the decrease in drug release rate due to swelling of the hydrophilic polymers used. In our present investigation selection of $\mathrm{HMWCH}$ and HPMC $\mathrm{K} 15 \mathrm{M}$ as polymer based on earlier studies based on these polymers (Soni et al., 2016) when in combination used it increases the viscosity of the system and helps in delaying the fraction drug releases due to the formation of hydrogel polymeric structure outside. The maximum swelling was found in CPR followed by HPMC K15M and HMWCH. This formulation has two types of hydrogel-forming structure which comprises of $\mathrm{HMWCH}$; ionic and $\mathrm{CPR}$ and HPMC K15M; non-ionic polymer. A given amount of force which is created by moving dissolution shaft, swelling of the ionic hydrogels will be more entropy favoured means as opposed by their non-ionic counterparts (Verma et al., 2012). Being cationic and non-ionic in nature, swelling of $\mathrm{HMWCH}, \mathrm{CPR}$ and HPMC K15M in acidic dissolution media will be a more entropy favoured process, due to number of ions in the hydrogel structure increases, more osmotic and immobile electrostatic force developed inside the polymeric structure (Soni et al., 2017a). It leads to the uptake of dissolution media and this hydrogel behaves like a liquid state as it occupies more space. Being carbohydrate 


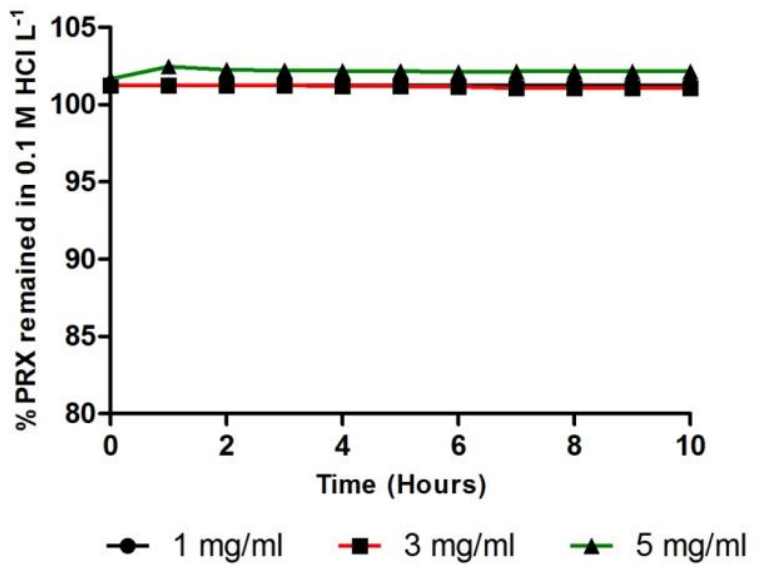

Figure 1: In vitro stability studies of PRX in $0.1 \mathrm{M} \mathrm{HCl}$.
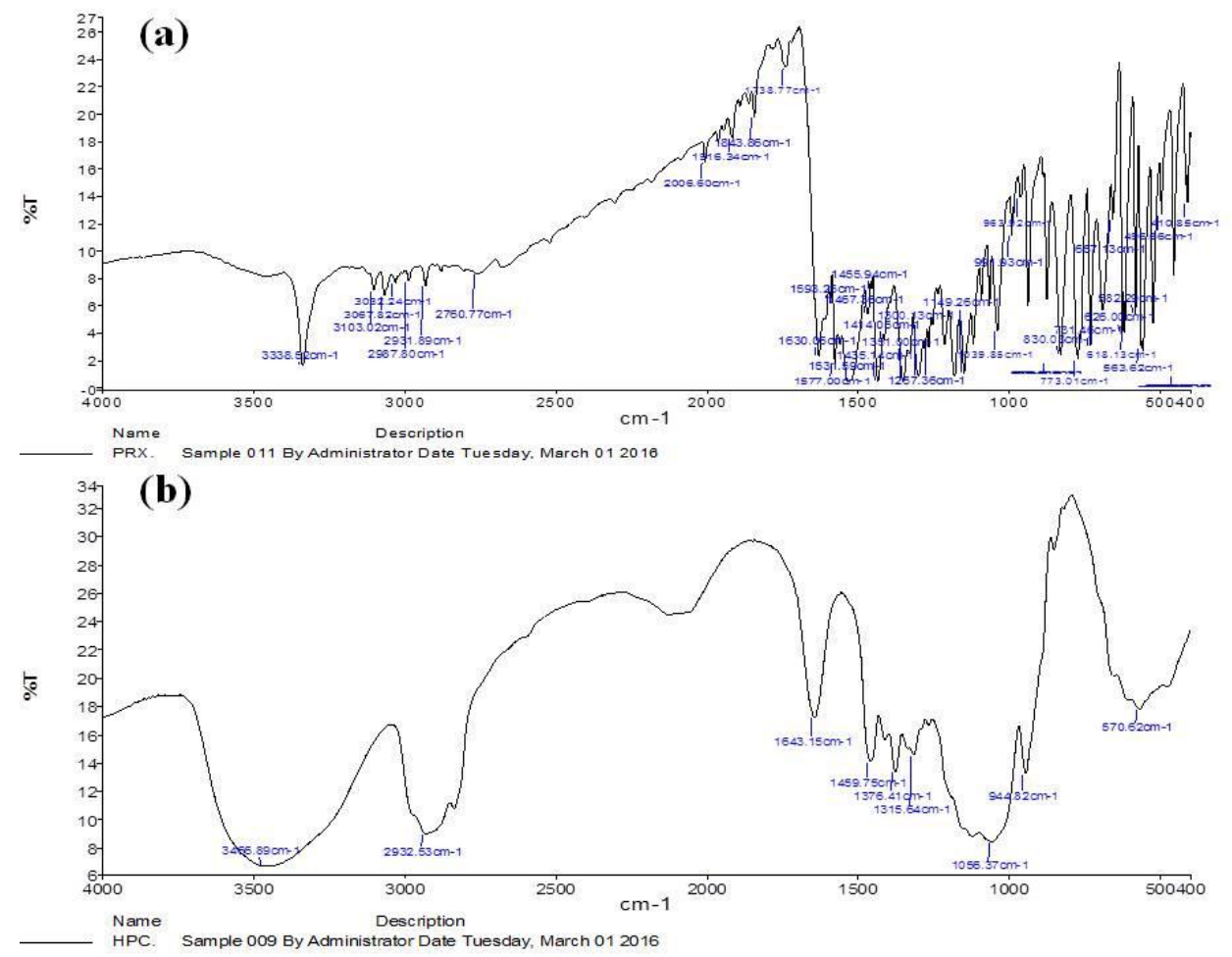

Figure 2: FTIR spectra of (a) PRX (b) HPMC K15M. 

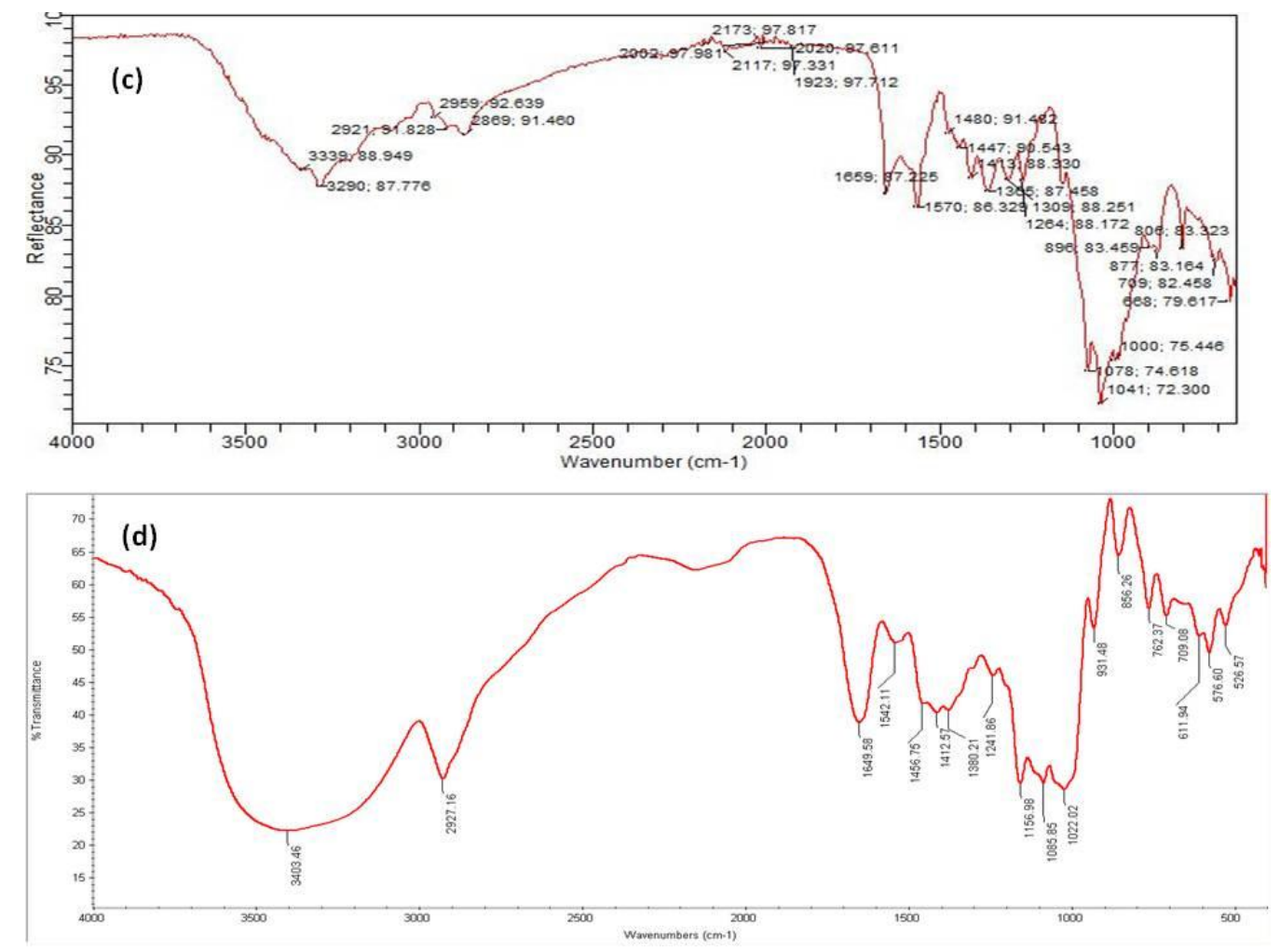

Figure 3: FTIR spectra of (c) HMWCH (d) CPR.
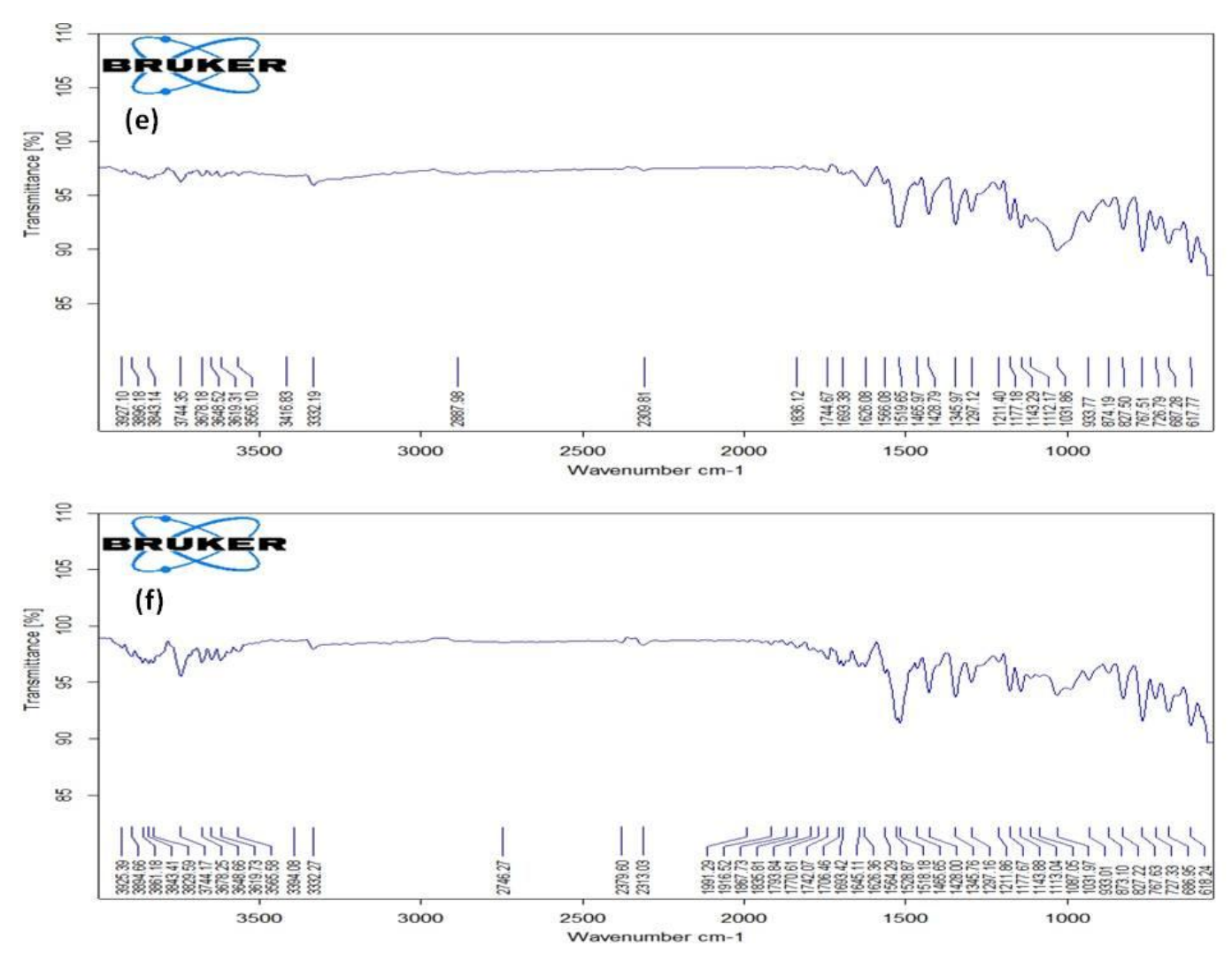

Figure 4: FTIR spectra of (e) PRX+HPMC+CPR (f) PRX+HMWCH+CPR. 


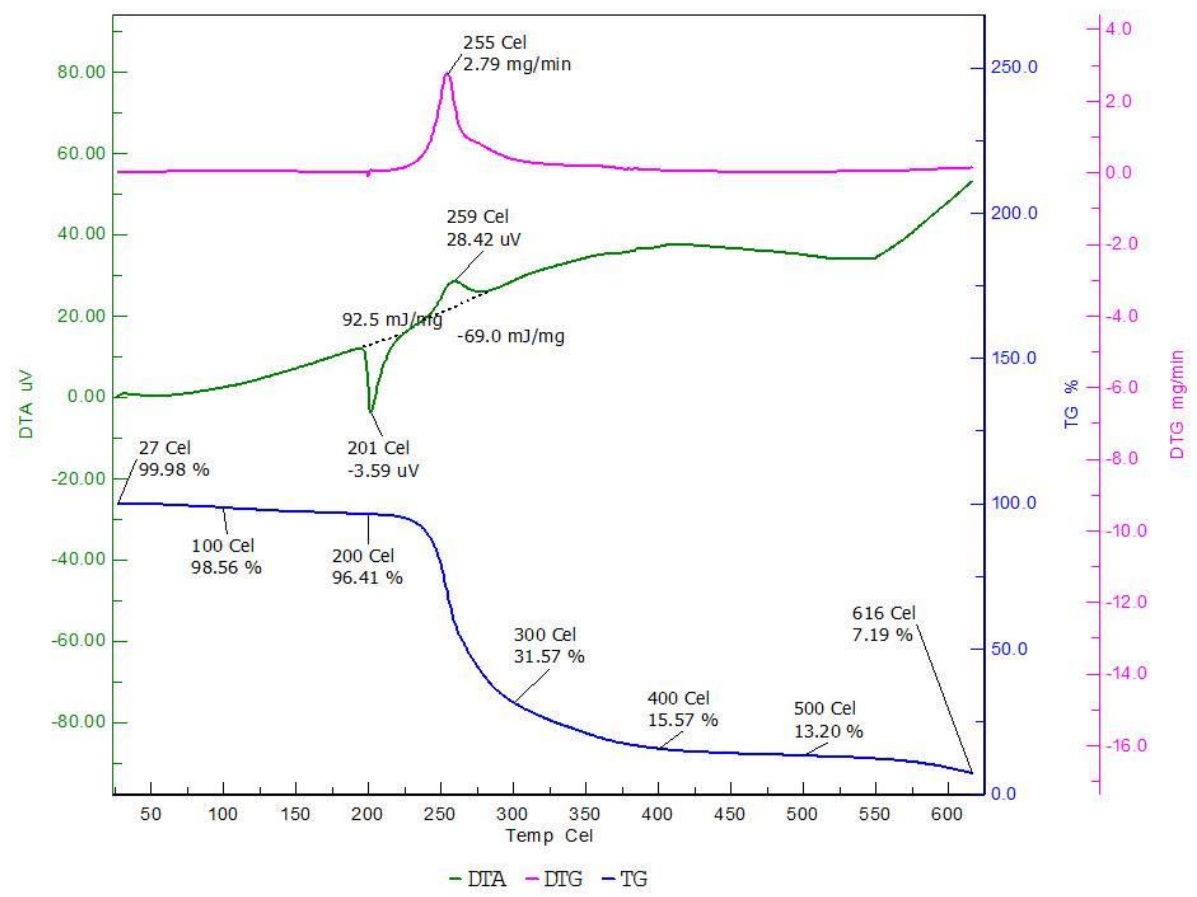

Figure 5: Thermogram of PRX.

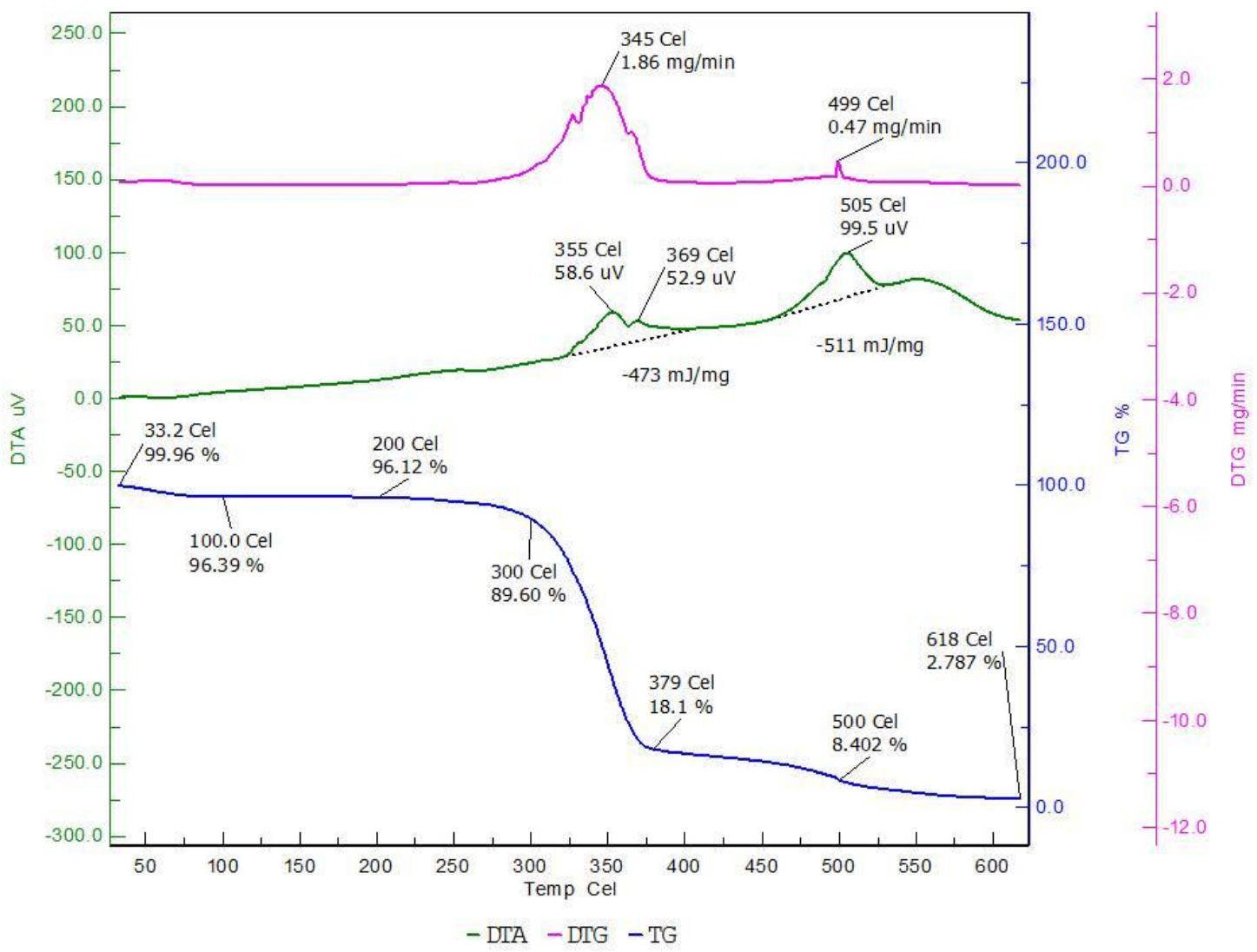

Figure 6: Thermogram of HPMC K15M. 


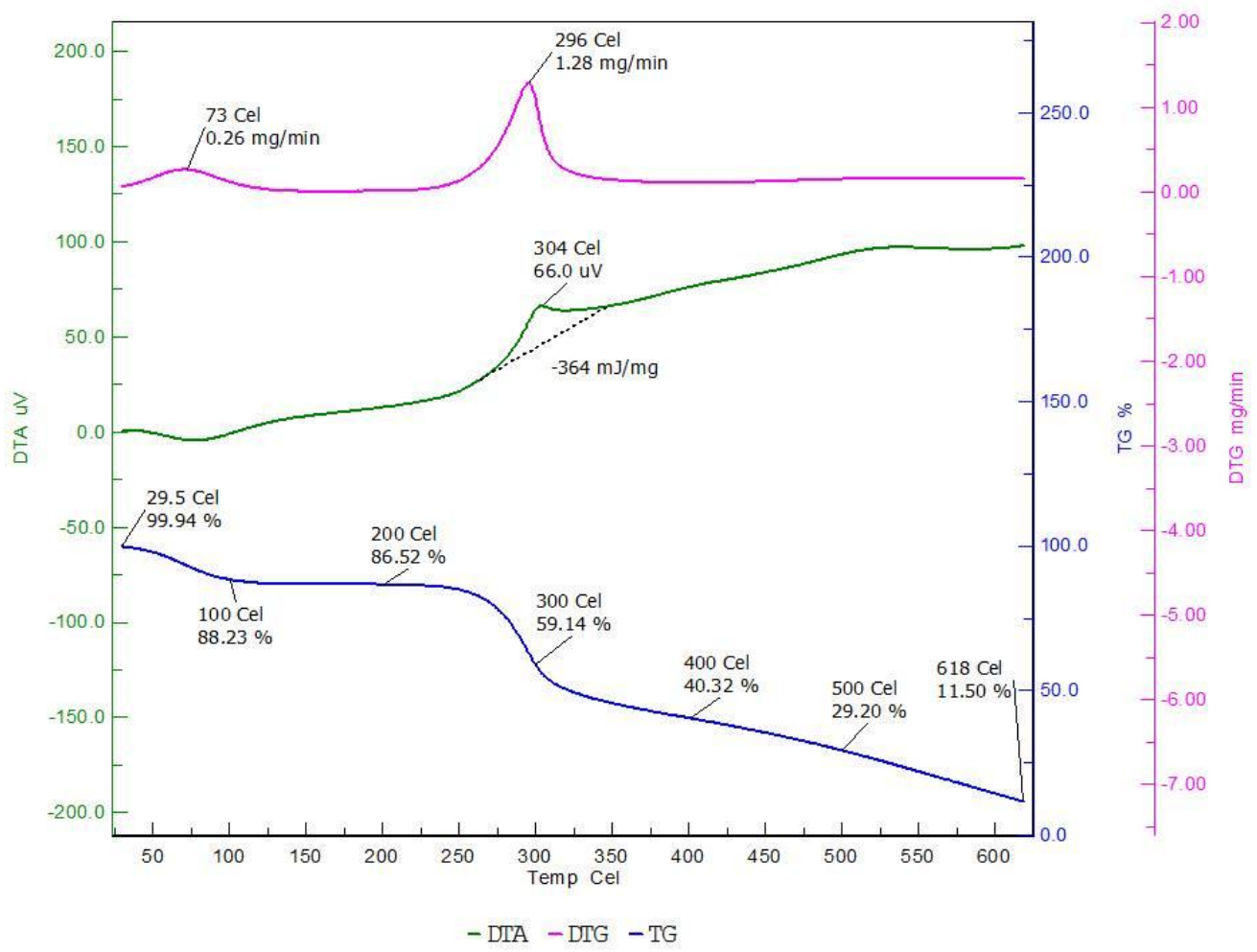

Figure 7: Thermogram of $\mathrm{HMWCH}$.

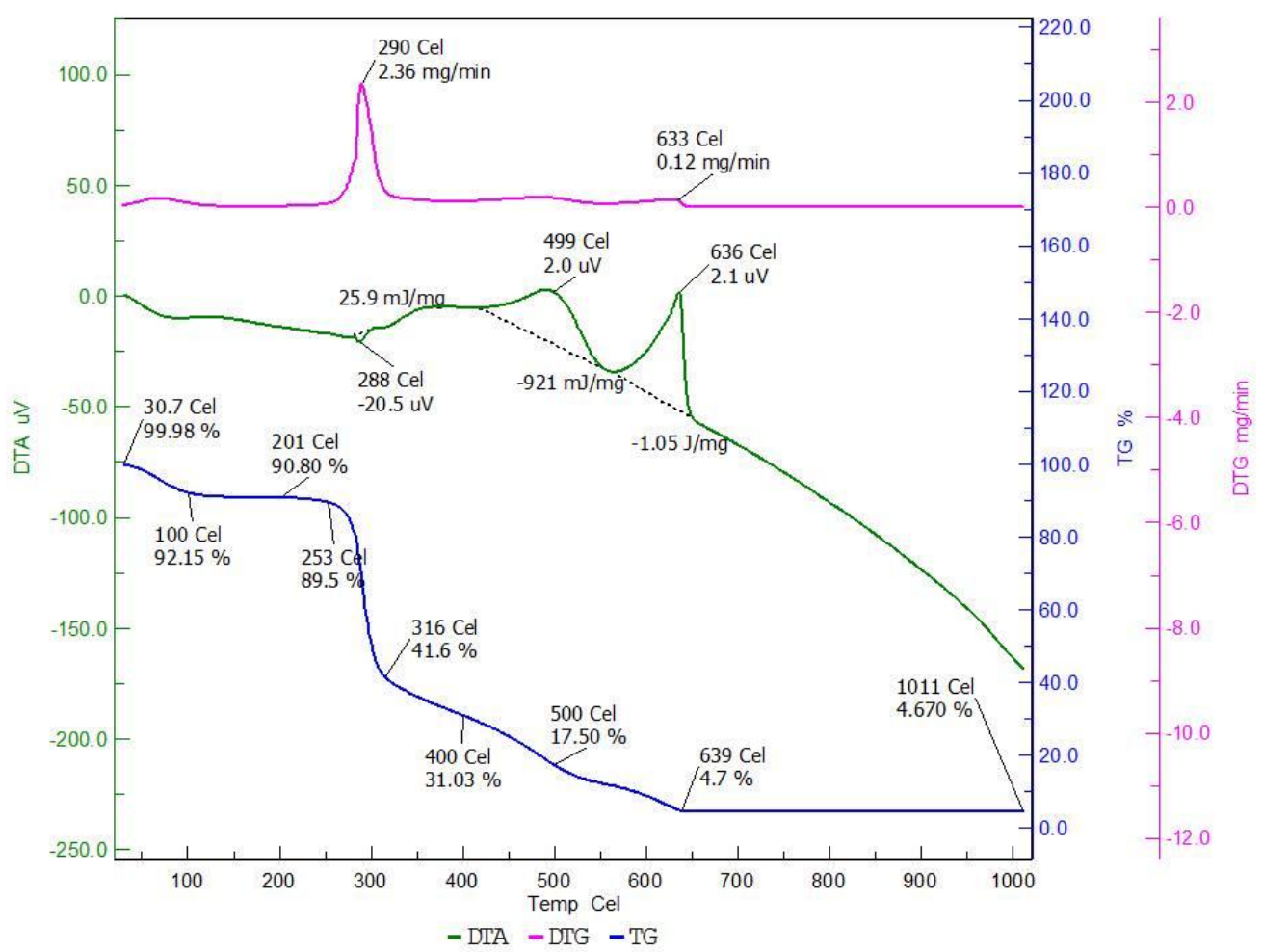

Figure 8: Thermogram of CPR. 


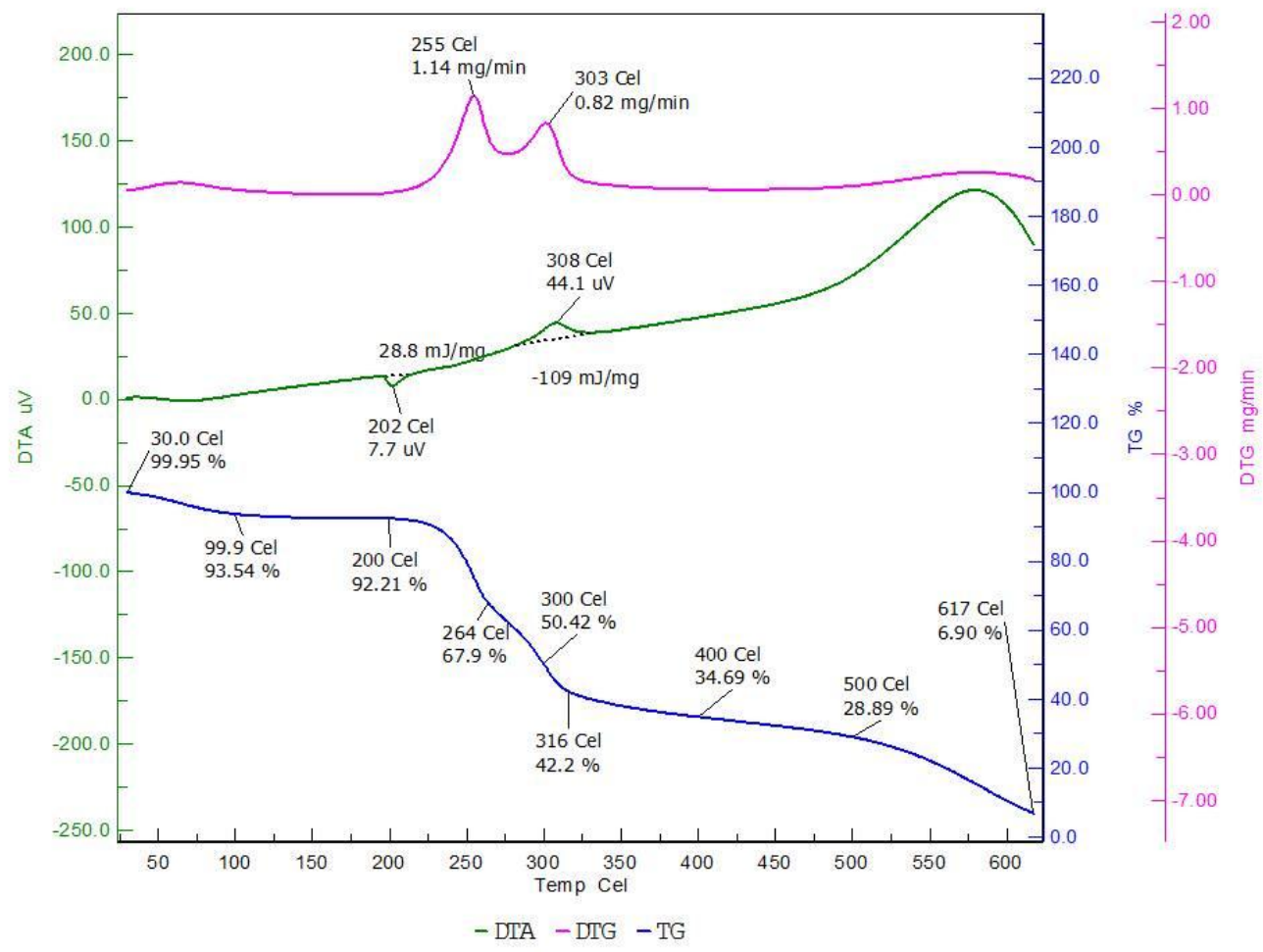

Figure 9: Thermogram of PRX + HMWCH.

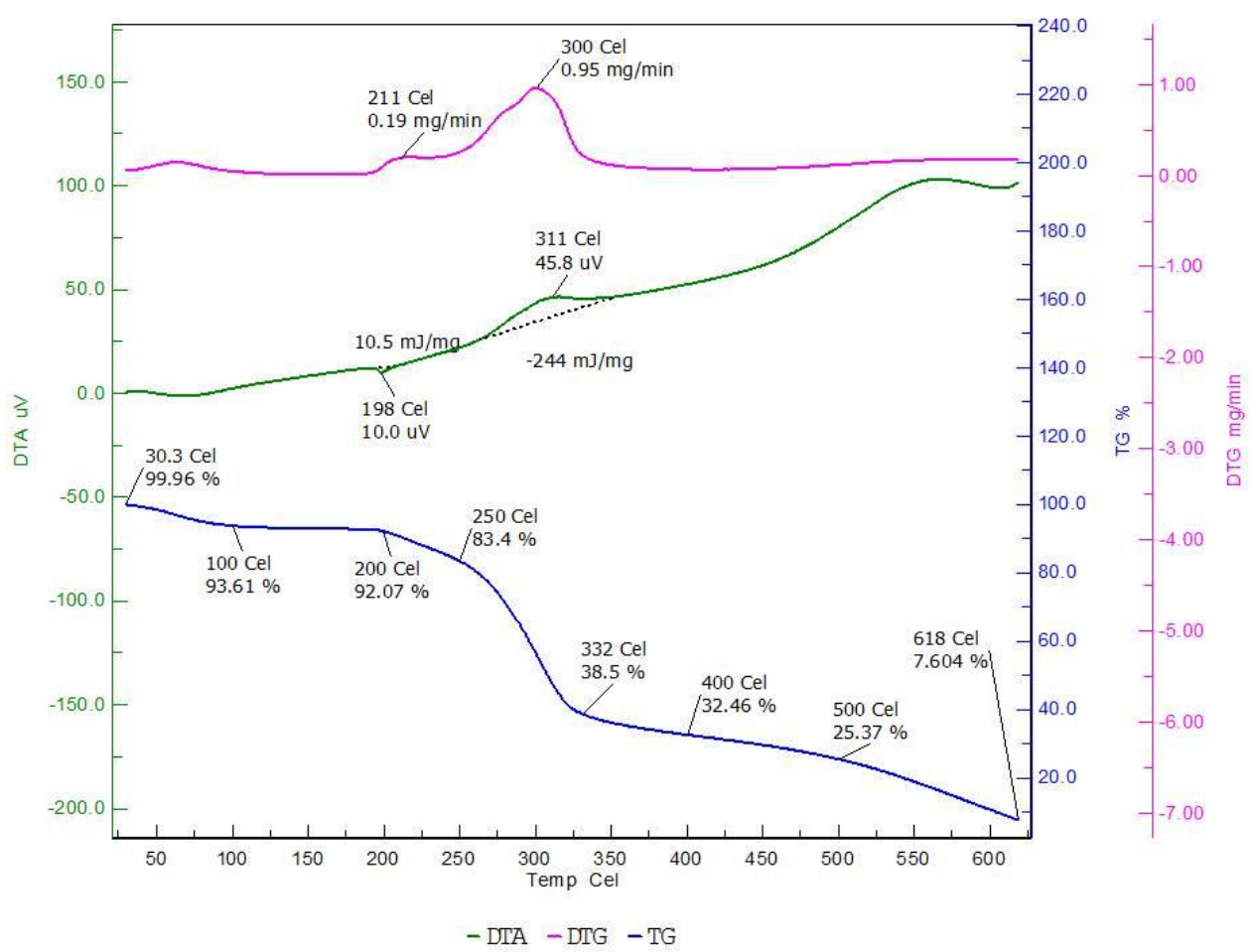

Figure 10: Thermogram of PRX + HMWCH + HPMC K15M. 


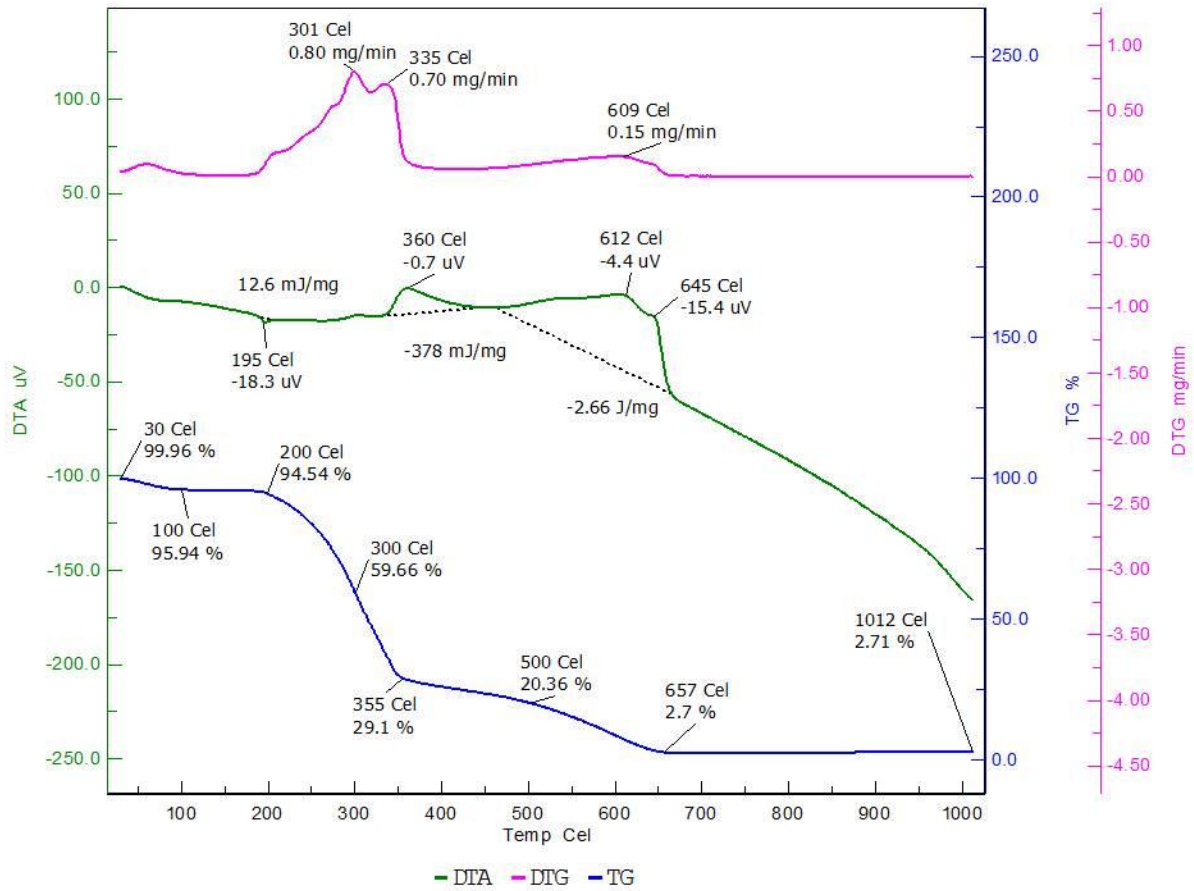

Figure 11: Thermogram of PRX + HMWCH + HPMC K15M + CPR.
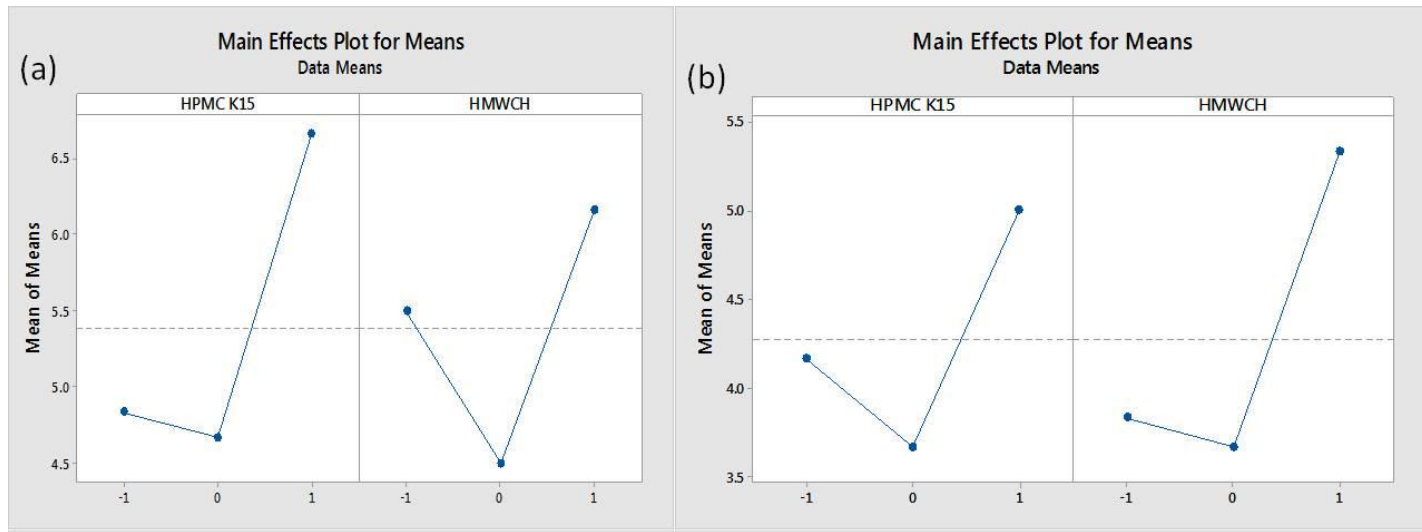

(C) Contour Plot of Buoyancy (Y 1) (hours) vs HPMC K15, HMWCH

(d) Contour Plot of T60\% (Y 2) (hours) vs HPMC K15, HMWCH
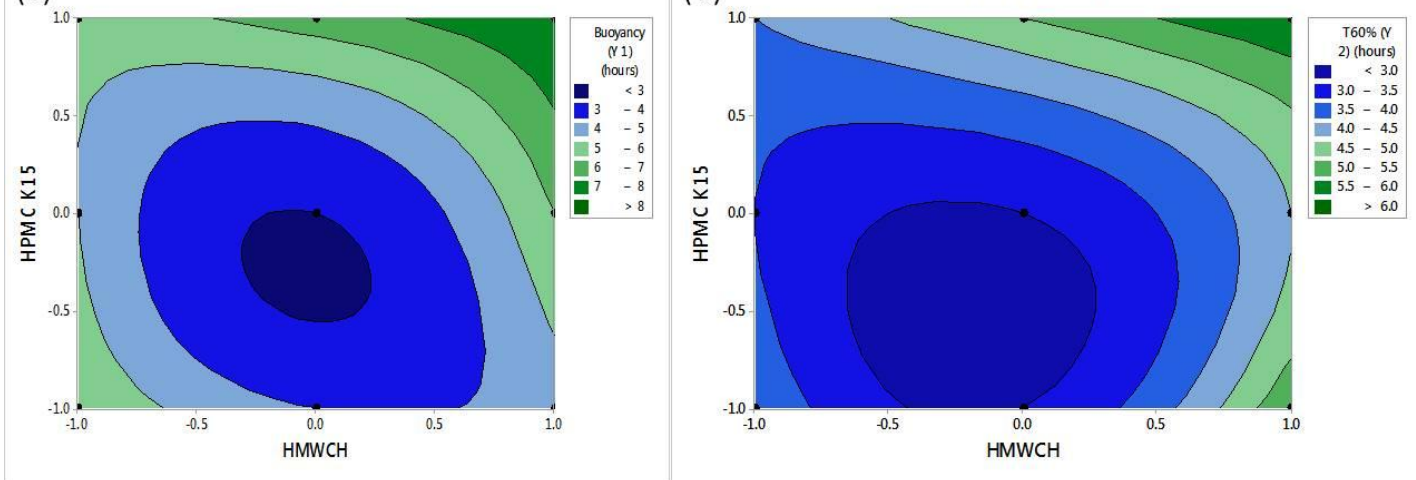

Figure 12: Representing (a) Mean effects plot for Means for buoyancy (b) Mean effects plot for Means for T 60\% drug release (c) Contour plot for buoyancy (d) Contour plot for T 60\% drug release. 


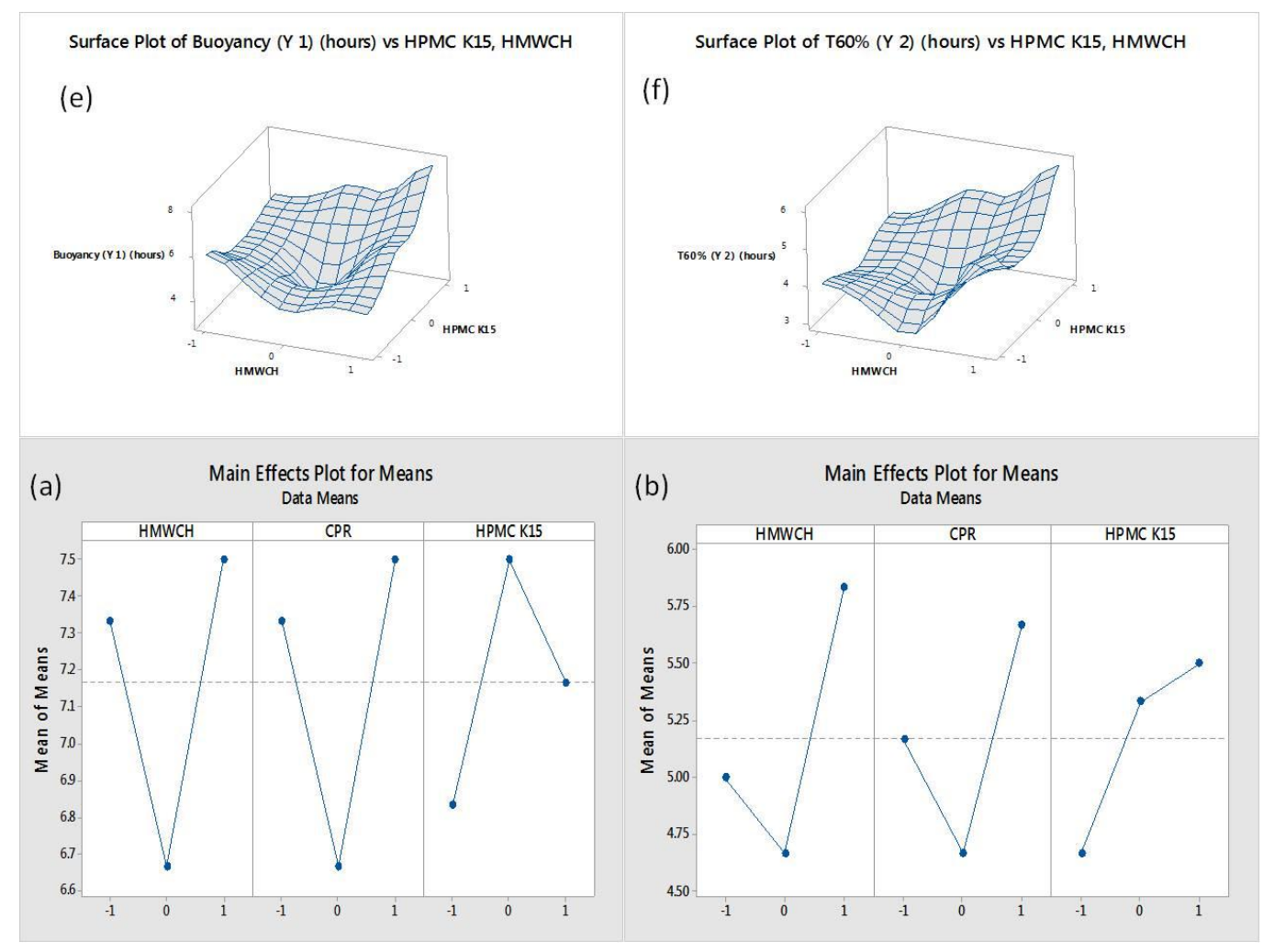

Figure 13: Representing (e) Wireframe surface plot for buoyancy (f) Wireframe surface plot for T60\% drug release (a) Main effects for means for buoyancy (T1-T9), (b) Main effects for means for T60\% drug release (T1-T9).
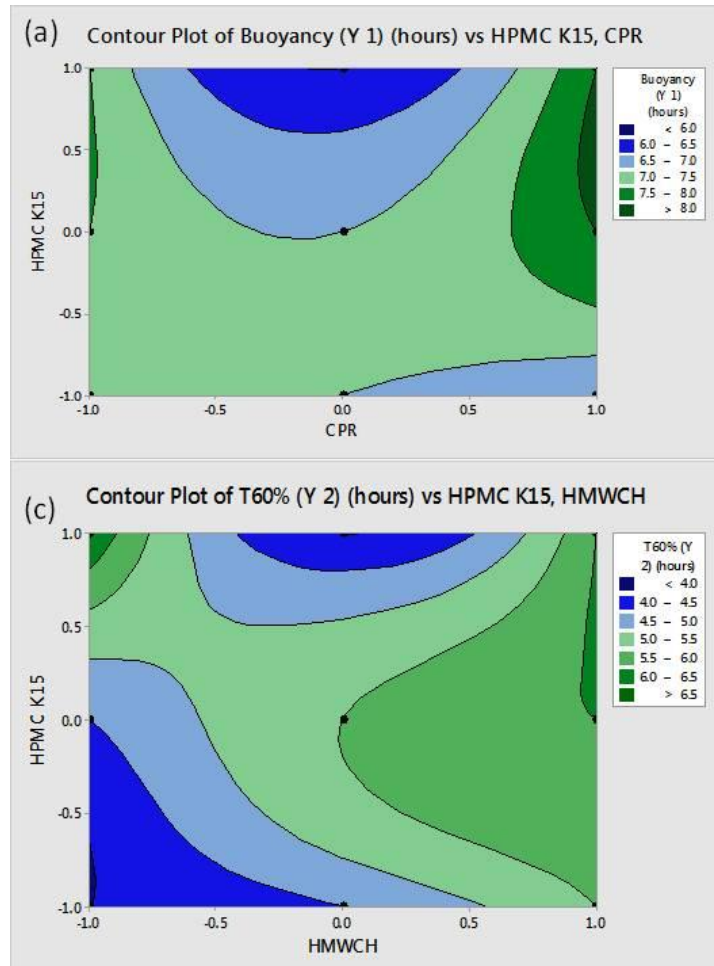

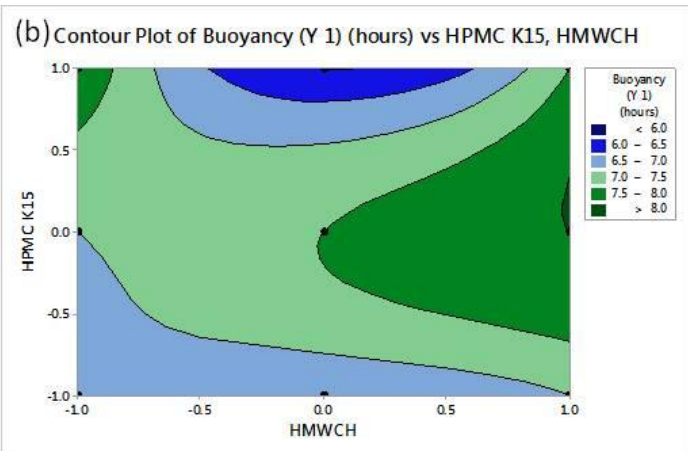

(d) Contour Plot of T60\% (Y 2) (hours) vs HPMC K15, CPR

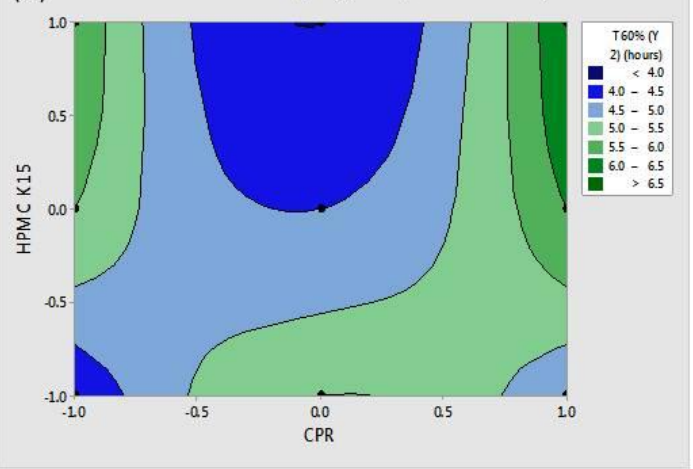

Figure 14: Representing (a) Contour plot for buoyancy using HPMC K 15 and CPR (b) Contour plot for buoyancy using HPMC K 15 and HMWCH (c) Contour plot for T60\% using HPMC K 15 and HMWCH (d) Contour plot for T60\% using HPMC K 15 and CPR. 
Surface Plot of T60\% (Y 2) (hours) vs HPMC K15, HMWCH

(a)

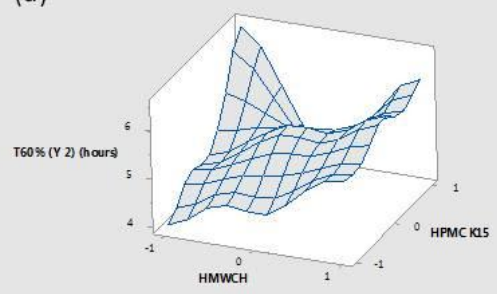

Surface Plot of Buoyancy (Y 1) (hours) vs HPMC K15, HMWCH

(c)

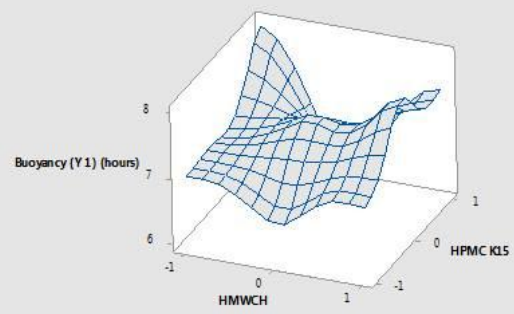

Surface Plot of T60\% (Y 2) (hours) vs HPMC K15, CPR

(b)

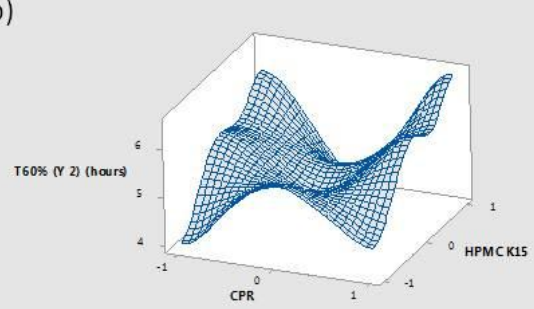

Surface Plot of Buoyancy (Y 1) (hours) vs HPMC K15, CPR

(d)

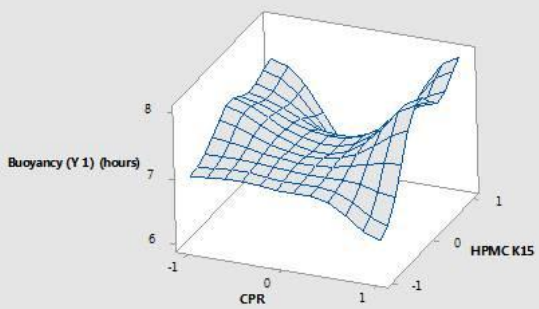

Figure 15: Representing (a) Wireframe surface plot for T60\% using HPMC K15M and HMWCH (b) Wireframe surface plot for T60\% drug release using HPMC K15M and CPR (c) Wireframe surface plot for buoyancy using HPMC K15M and HMWCH (d) Wireframe surface plot for buoyancy using HPMC K15M and CPR.

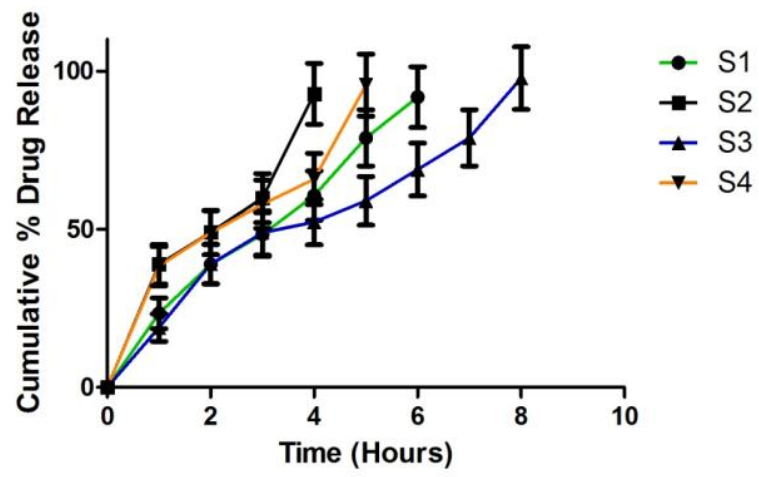

Figure 16: Cumulative\% Drug Release of formulations S1 - S4.

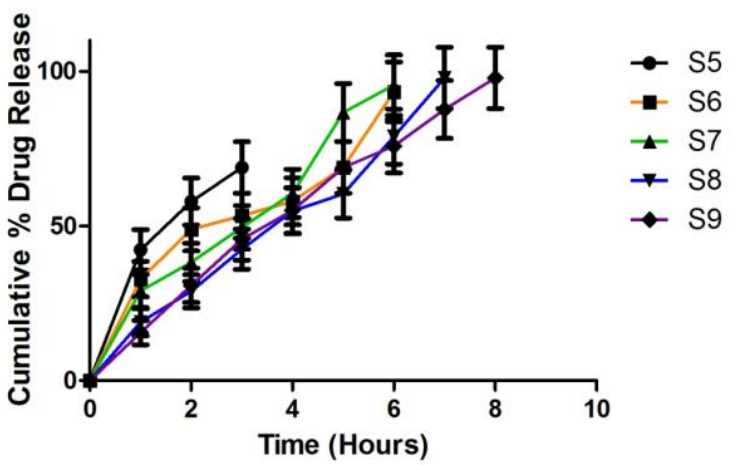

Figure 17: Cumulative Percent Drug Release of formulations S5 - S9. 


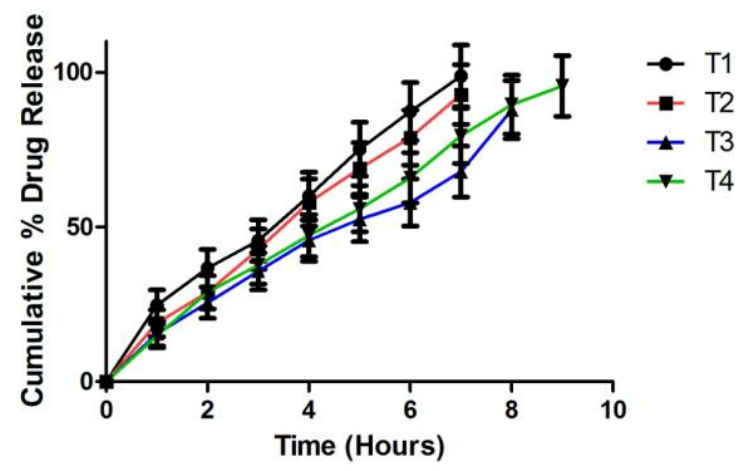

Figure 18: Cumulative Percent Drug Release of formulations T1 - T4.

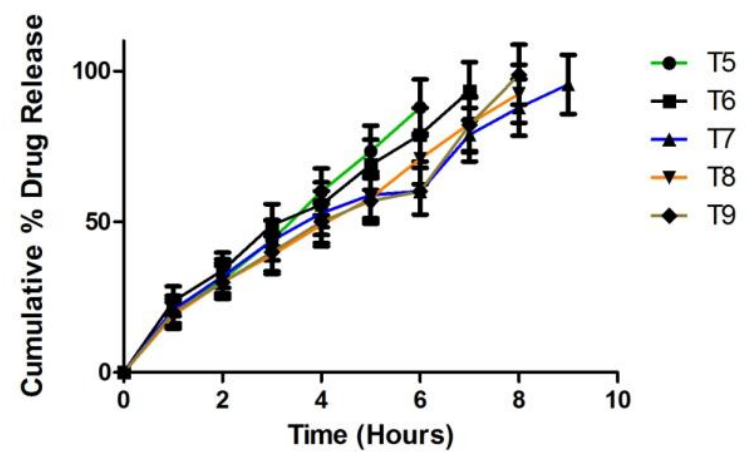

Figure 19: Cumulative Percent Drug Release of formulations T5 - T9.

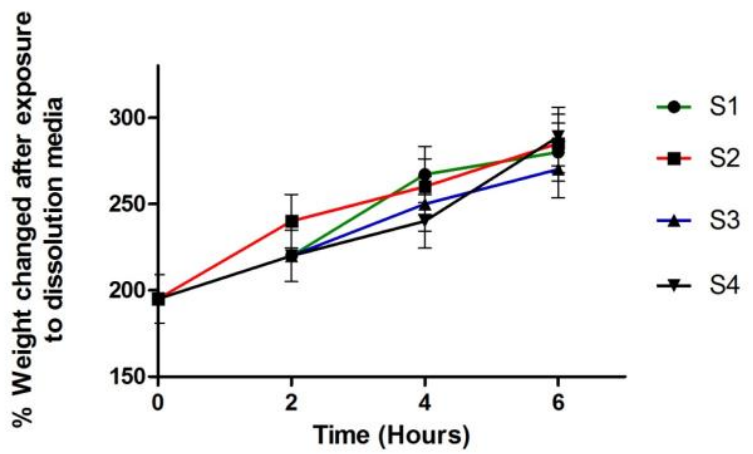

Figure 20: Percent Weight changed of formulations S1 - S4 in dialysis bag (1000 Da, Molecular weight) after exposure to dissolution media in $0.1 \mathrm{M} \mathrm{HCl}$. 


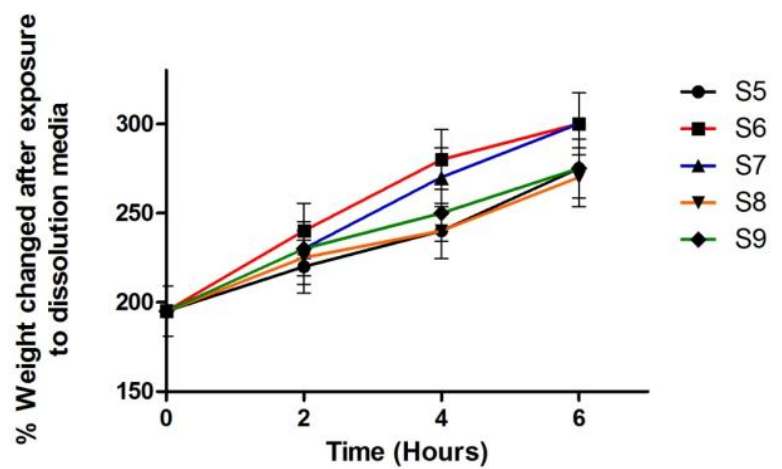

Figure 21: Percent Weight changed of formulations S5 - S9 in dialysis bag (1000 Da, Molecular weight) after exposure to dissolution media in $0.1 \mathrm{M} \mathrm{HCl}$.

in nature CPR contains carbon, hydrogen, and carbon, they regarded as hydrates of carbon. It is dispersible in warm water to form high gel strength. No work till reported by using this CPR for stomach specific drug delivery. It was believed that the incorporation of CPR with anionic $\mathrm{HMWCH}$ and non-ionic HPMC polymer will increase the viscosity of gelled polymer which provides the more resistance to the diffusion of PRX through the gelled glassy polymeric structure. It was observed that the incorporation of CPR leads to the plug formation instead of gelled polymeric structure. During this PRX release was found to be negligible $(<0.1 \%)$. Total time spent for the plug formation ranges from 10-15 minutes. However, in all the formulations in the initial first-hour average drug release fraction is $22 \%$. This is possible due to time spent on plug formation and during this period drug not hold inside the matrix for that particular period of time and leaches out. Once the plug formation is achieved PRX release was significantly retarded with the next $60 \%$ for the average time period of 10 hours. All these formulations release the drug for a time period of 07-10 hours without showing any burst effect. Combining the CPR with $\mathrm{HMWCH}$ and cellulosic derivatives leads to increase in gel strength and retards the release of PRX from the matrix. CPR in combination with $\mathrm{HMWCH}$ and hypromellose leads to the development of swelling glassy matrix and conversion to the glassy polymeric structure to soft rubbery like structures. CPR shows excellent retarding property without showing any burst effect followed by zero order kinetics throughout the period of time. Formulation S1-S6 and S7-S9 the drug release pattern is significantly different to each other $(p<0.05)$ and $(p$ $=0.0008)$ and same with the case for formulation T1-T9 $(p<$ $0.05)$ and $(p=0.0008)$ The amount of PRX loading in the formulations leads to the coining of PRX inside the polymeric structures when it comes in contact with the dissolution fluid. The possible reason behind this type of behaviour is due to the PRX is having the pka value 4.76 (strongest acidic) and when it comes in $\mathrm{pH}$ of 1.2 it remains in unionize form and delayed in dissolution rate of PRX.

\section{In vitro buoyancy studies for formulations}

For efficient buoyancy, swelling of the polymer is a key important parameter. Addition to these there must be proper control of swelling, water uptake and hydration of the polymer and this can be regulated by the proper selection of polymer. In this investigation, swelling of the polymer resulted in an increase in bulk volume. The air entrapped resulted in density lesser than the utility, which ultimately leads to the buoyancy to the formulation without showing any lag time (Verma et al., 2012; Soni et al., 2016; Soni et al., 2017a) [Table 13 and 14].

Drug release rate depends on the dissolution media penetration rate, swelling behaviour of the polymer, diffusion efflux of drug through the matrixes after erosion when it gets in contact with the dissolution media. From the data obtained from release kinetics formulations, S1-S9 follows zero order kinetics which is shown by its $\mathrm{r}^{2}$ value. Zero-order kinetics refers the nearly uniform drug release rate, which is independent of its concentration of the drug; this type of pharmaceutical system shows minimum side effects (Soni et al., 2106). Zero-order kinetics $\mathrm{r}^{2}$ value ranges from 0.8995 to 0.9993 for S1-S9 and 0.9748-0.9998 for T1-T9 and $\mathrm{n}$ value ranges from 0.39 to 0.57 and $0.40-0.45$ respectively for S1-S9 and T1-T9. Formulation (S1-S9 and T1-T9) follows the Fickian model of drug release. It means that the drug release from the polymeric system is controlled by the development of hydrogel barrier. When these formulations come in contact with the dissolution medium due to hydration it causes swelling and expansion which leads the development of three fonts: swelling font, diffusion and erosion font and all three fonts are the rate limiting parameter for the apparent motion of macromolecules from the matrix. Fickian diffusion release occurs by molecular diffusion of the drug due to a chemical potential gradient. In addition to drug release kinetics, Akaike Information Criterion (AIC) was also determined which is a measurement of goodness of fit (Soni et al., 2016; Soni et al., 2017). When compared with models of data, the model represents with the smallest AIC value is considered as a best fit model. AIC values determination confirms the formulations S1-S9 and T1-T9 follows zero order kinetics [Table 15 and 16].

\section{CONCLUSION}

The formulation of PRX was prepared by using polymers like CPR, HMWCH and HPMC K15M as polymers using the 3 (2) Taguchi factorial design of experiments (Minitab18) and optimized by using RSM plot involving the factor as gel-forming property for formulations S1-S9 and T1-T9 and response taken as buoyancy time $\left(\mathrm{Y}_{1}\right)$ and $\mathrm{T} 60 \%$ drug release $\left(\mathrm{Y}_{2}\right)$ from the HBS capsules. Formulation $\mathrm{S} 1, \mathrm{~S} 4$, and S6-S9 were found to be optimized with showing desirable buoyancy time and drug release in the acidic gastric environmental region. While in case of formulation T1-T9 all the formulation showing desirable buoyancy time and drug release in the acidic gastric environment. This is attributed due to the incorporation of CPR acts as a buoyancy imparting as well PRX retarding polymer in the gastric environment. From these studies, we can say that CPR can be used as biopolymer for sustaining the release of drug from the polymeric matrixes and also as buoyancy imparting agent which is an important tool for achieving gastroretention. Further, this biopolymer needs an exploration for delivery of the drug as a carrier at different sites at different $\mathrm{pH}$ conditions. Formulation S9, T3 and T9 can be further extended for in vivo experimental studies like gamma scintigraphic and bio-distribution animal studies.

ACKNOWLEDGEMENT

This research work was gently supported by Sardar Bhagwan Singh PG Institute of Biomedical Sciences and Research, Dehradun, India. Authors are also thankful to IIT; Roorkee, India for characterization of samples. 


\section{REFERENCES}

Bernkop-Schnürch, A., \& Dünnhaupt, S. (2012). Chitosan-based drug delivery systems. European Journal of Pharmaceutics and Biopharmaceutics, 81(3), 463-469. [DOI]

Cervera, M. F., Karjalainen, M., Airaksinen, S., Rantanen, J., Krogars, K., Heinämäki, J. \& Yliruusi, J. (2004). Physical stability and moisture sorption of aqueous chitosan-amylose starch films plasticized with polyols. European journal of pharmaceutics and biopharmaceutics, 58(1), 6976. [DOI]

Dubey, J., Verma, A., \& Verma, N. (2015). Evaluation of chitosan based polymeric matrices for sustained stomach specific delivery of propranolol hydrochloride. Indian Journal of Materials Science, 2015. [DOI]

Dürig, T., \& Fassihi, R. (2002). Guar-based monolithic matrix systems: effect of ionizable and non-ionizable substances and excipients on gel dynamics and release kinetics. Journal of controlled release, 80(1-3), 45-56. [DOI]

Haug, A., Larsen, B., \& Smidsrod, O. (1967). Studies on the sequence of uronic acid residues in alginic acid. Acta chem. scand, 21(3), 691-704. [DOI]

Huang, Y., Tang, J., Swanson, B. G., \& Rasco, B. A. (2003). Effect of calcium concentration on textural properties of high and low acyl mixed gellan gels. Carbohydrate Polymers, 54(4), 517-522. [DOI]

Jarry, C., Leroux, J. C., Haeck, J., \& Chaput, C. (2002). Irradiating or autoclaving chitosan/polyol solutions: effect on thermogelling chitosan- $\beta$ glycerophosphate systems. Chemical and pharmaceutical bulletin, 50(10), 1335-1340. [DOI]

Khoo, C. G., Frantzich, S., Rosinski, A., Sjöström, M., \& Hoogstraate, J. (2003) Oral gingival delivery systems from chitosan blends with hydrophilic polymers. European Journal of Pharmaceutics and Biopharmaceutics, 55(1), 47-56. [DOI]

Kizil, R., Irudayaraj, J., \& Seetharaman, K. (2002). Characterization of irradiated starches by using FT-Raman and FTIR spectroscopy. Journal of agricultural and food chemistry, 50(14), 3912-3918. [DOI]

Kumar, L., Reddy, M. S., Managuli, R. S., \& Pai, G. (2015). Full factorial design for optimization, development and validation of HPLC method to determine valsartan in nanoparticles. Saudi Pharmaceutical Journal, 23(5), 549-555. [DOI]

Lemaire, V., Belair, J., \& Hildgen, P. (2003). Structural modeling of drug release from biodegradable porous matrices based on a combined diffusion/erosion process. International journal of pharmaceutics, 258(1-2), 95-107. [DOI]

Li, S., Lin, S., Daggy, B. P., Mirchandani, H. L., \& Chien, Y. W. (2003). Effect of HPMC and carbopol on the release and floating properties of gastric floating drug delivery system using factorial design. International journal of pharmaceutics, 253(1-2), 13-22. [DOI]
Mucha, M. Ludwiczak, S , \& Kawinska, M. (2005). Kinetics of water sorption by chitosan and its blends with poly (vinyl alcohol). Carbohydrate Polymers, 62(1), 42-49. [DOI]

Omidian, H., \& Park, K. (2008). Swelling agents and devices in oral drug delivery. Journal of Drug Delivery Science and Technology, 18(2), 83-93. [DOI]

Santha, N., Sudha, K. G., Vijayakumari, K. P., Nayar, V. U., \& Moorthy, S. N. (1990). Raman and infrared spectra of starch samples of sweet potato and cassava. Journal of Chemical Sciences, 102(5), 705-712. [DOI]

Saxena, A., Mishra, A. K., Verma, N., Bhattacharya, S. S., Ghosh, A., Verma A., \& Pandit, J. K. (2013). Gelucire based in situ gelling emulsions: a potential carrier for sustained stomach specific delivery of gastric irritant drugs. BioMed research international, 2013. [DOI]

Siepmann, J., \& Göpferich, A. (2001). Mathematical modeling of bioerodible, polymeric drug delivery systems. Advanced drug delivery reviews, 48(2-3), 229-247. [DOI]

Soni, S., Ram, V., \& Verma, A. (2017a). Crushed Puffed Rice-HPMCChitosan based Single-Unit Hydro-dynamically Balanced System for the Sustained Stomach Specific Delivery of Metoprolol Succinate. Journal of Applied Pharmaceutical Science, 7(12), 047-057. [DOI]

Soni S, Verma A, Ram V. (2016). Evaluation of Chitosan-Hydroxy Propyl Methyl Cellulose as a Single Unit Hydrodynamically Balanced Sustained Release Matrices for Stomach Specific Delivery of Piroxicam. MOJ Bioequiv Availab, 1(3): 00014. [DOI]

Soni, S., Verma, N., Verma, A., \& Pandit, J. K. (2017). Gelucire based floating emulsion gel beads: a potential carrier for sustained stomach specific drug delivery. Farmacia, 65(1), 142-152.

Verma, A., Bansal, A., Ghosh, A., \& Pandit, J. (2012). Low molecular mass chitosan as carrier for a hydrodynamically balanced system for sustained delivery of ciprofloxacin hydrochloride. Acta Pharmaceutica, 62(2), 237-250. [DOI]

Verma, A., Dubey, J., Verma, N., \& Kumar Nayak, A. (2017). Chitosan-Hydroxypropyl Methylcellulose Matrices as Carriers for Hydrodynamically Balanced Capsules of Moxifloxacin $\mathrm{HCl}$. Current drug delivery, 14(1), 83-90. [DOI]

Wilson, R. H., Goodfellow, B. J., Belton, P. S., Osborne, B. G., Oliver, G., \& Russell, P. L. (1991). Comparison of Fourier transform mid infrared spectroscopy and near infrared reflectance spectroscopy with differentia scanning calorimetry for the study of the staling of bread. Journal of the Science of Food and Agriculture, 54(3), 471-483. [DOI] 